EXAMINING THE RELATIONSHIP

BETWEEN TRUST AND ONLINE USAGE OF NEWS MEDIA

A Thesis

Presented to

the Faculty of the Graduate School

at the University of Missouri

In Partial Fulfillment

of the Requirements for the Degree

Master of Arts

by

KATHRYN YAEGER

Dr. Harsh Taneja, Thesis Supervisor

MAY 2017 
(C) Copyright by Kathryn Yaeger, 2017

All Rights Reserved 
The undersigned, appointed by the dean of the Graduate School, have examined the thesis entitled

EXAMINING THE RELATIONSHIP

\section{BETWEEN TRUST AND ONLINE USAGE OF NEWS MEDIA}

presented by Kathryn Yaeger,

a candidate for the degree of Master of Arts,

and hereby certify that, in their opinion, it is worthy of acceptance.

Professor Harsh Taneja

Professor Ryan Thomas

Professor Timothy Vos

Professor Benjamin Warner 


\section{DEDICATION}

To my parents: Thanks for being unconditionally supportive of my ever-evolving interests and for encouraging me to pursue a graduate degree.

To my friends: Thanks for making this Missouri town a fun place to stick around for another two years. 


\section{ACKNOWLEDGEMENTS}

I would like to first thank my thesis supervisor and methodologist, Dr. Harsh Taneja, for his unwavering, invaluable input and guidance throughout the thesis process. Without his suggestions about incorporating usage theories, assistance with R commands and econometrics interpretations, and careful, detailed feedback on drafts and during meetings, the process would not have gone as smoothly, and this thesis would not be the product it is today.

I also would like to thank the members of my thesis committee - Dr. Tim Vos, Dr. Ryan Thomas and Dr. Ben Warner — for their constructive feedback and thoughtprovoking questions, particularly during the proposal, that polished this thesis further.

Finally, I would like to thank my professors in the School of Journalism, Robert J. Trulaske, Sr. College of Business, and Harry S. Truman School of Public Affairs especially Jim Flink, Joy Mayer, Mike Jenner and Randy Smith — for encouraging me inside and outside of class to ask questions, challenge the norm, think differently, solve problems creatively yet strategically, and pursue interests in topics that led to the creation of this thesis. 


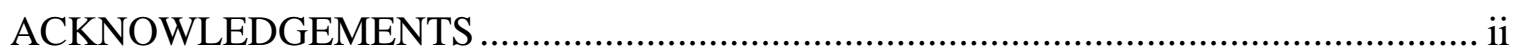

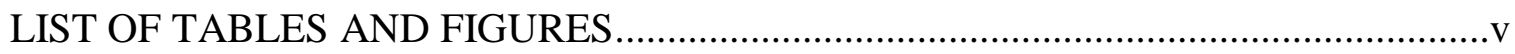

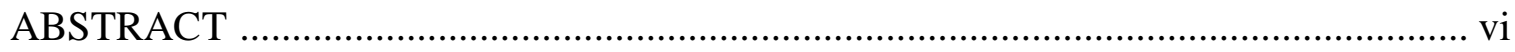

\section{Chapter}

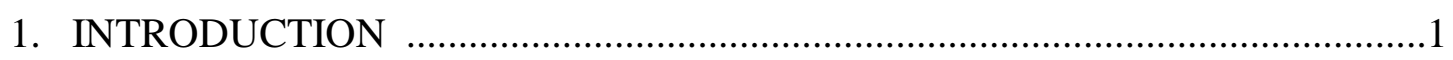

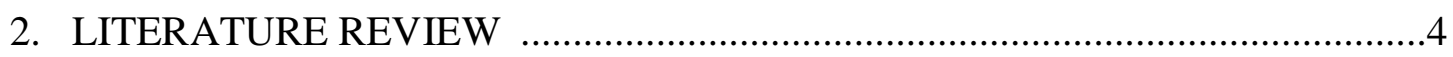

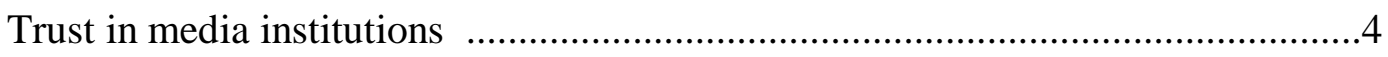

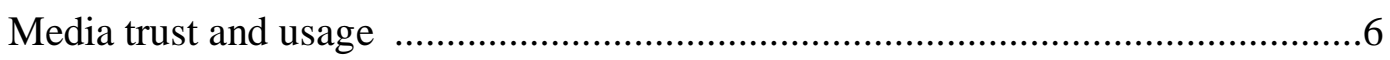

Complications of news media choice ……………........................................11

Research questions and hypothesis .................................................................15

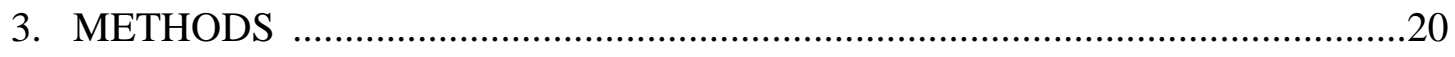

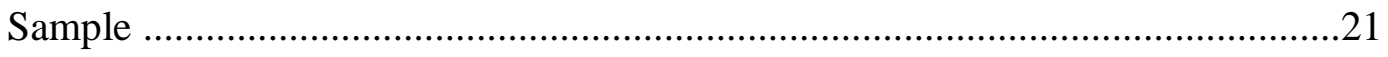

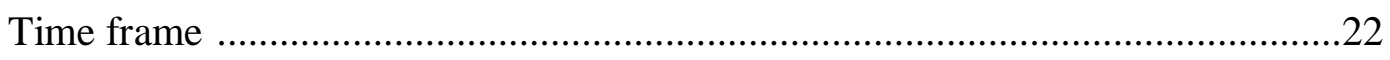

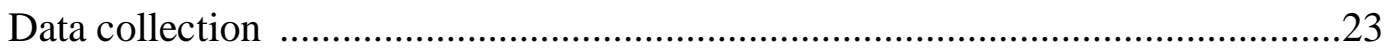

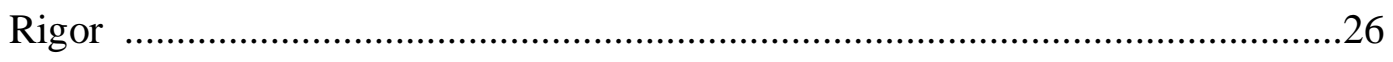

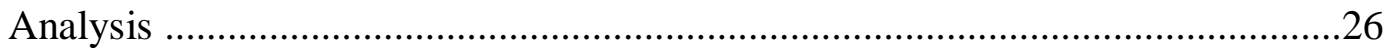

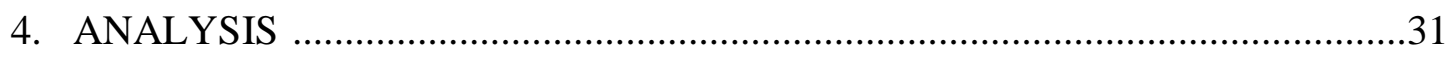

Correlation between trust of a news organization and frequent usage ..................34

Correlation between trust of a news organization and direct traffic ......................34 
5. DISCUSSION

Associations between trust and usage ............................................................39

Impact of other factors on trust and usage ..................................................41

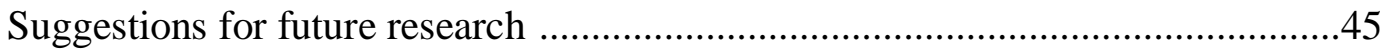

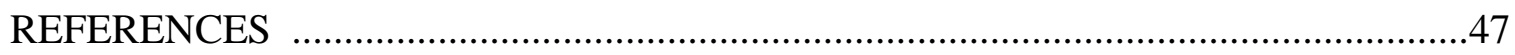

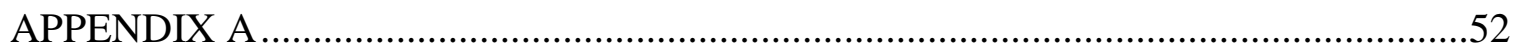

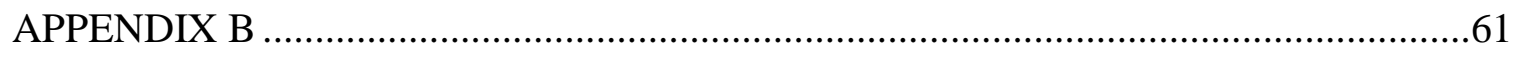




\section{LIST OF TABLES AND FIGURES}

1. Table 1: Correlation Matrix Between Dependent Variables ................................32

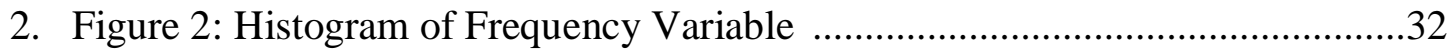

3. Figure 3: Histogram of Logarithm of Frequency Variable .................................33

4. Table 4: Regression Model to Explain Trustworthiness and Frequent Usage ......34

5. Table 5: Regression Models to Explain Trustworthiness and Direct Traffic .......37 


\title{
EXAMINING THE RELATIONSHIP BETWEEN \\ TRUST AND ONLINE USAGE OF NEWS MEDIA
}

\author{
Kathryn Yaeger
}

Dr. Harsh Taneja, Thesis Supervisor

\begin{abstract}
This study tests the relationship between overall trust and online usage of 35 popular United States news sources. Trust of news media, currently at its lowest percentage in Gallup's 45-year polling history, has both brand and financial impacts; as news organizations employ strategies to rebuild trust, knowing the relationship between trust and usage can help them measure the effectiveness of their efforts. A series of regression models using three months of pooled cross-sectional data of trust measures from the Pew Research Center and usage measures from ComScore found a positive, statistically significant relationship between trust and direct traffic, but it found no association between trust and frequent usage. When testing how additional variables moderated the relationship between trust and frequent traffic, the study found no evidence that having a multiplatform presence or political ideology impacted the relationship. It found evidence in one month that being a mainstream news source could impact this relationship, but results are overall inconclusive.
\end{abstract}




\section{Chapter 1: Introduction}

Eroding audience trust is a major problem facing news organizations today. In 2016, only 32 percent of Americans trusted the news media a great deal or a fair amount — the lowest percentage since Gallup started asking that question in 1972 (Swift, 2016). In a digital-centric world with more sources of information easily accessible at news consumers' fingertips than ever before, news organizations must find ways to regain audience trust and recapture audience attention before people shift it to other information

sources. This is no easy task, especially as the prevalence of curated distribution models, such as information feeds on social networks and search engine results pages, have introduced new ways of presenting information that could impact what people consume and what they trust. Distrust of a news organization can lead to serious implications, especially for an industry dependent on attention that strives to provide the public with information to make better democratic and lifestyle choices.

Decreased trust in news organizations can lead to not only damaged brand equities and images, but also serious financial consequences. In The Elements of Journalism, Bill Kovach and Tom Rosenstiel (2007) assert that by creating relationships with audiences that are founded on "values, trust, judgment, authority, courage, professionalism, and commitment to the community" (p. 64), news organizations create a value proposition attractive to advertisers, who have historically paid for much of news media. When those relationships with audience members are compromised, that value proposition becomes less attractive to advertisers, who could lessen or cease advertising, therefore funneling less money into the news media industry and forcing publishers to 
seek other sources of funding. Research by the Media Insight Project, an initiative of the American Press Institute and the Associated Press-NORC Center for Public Affairs Research, also found that news consumers who place more importance on trustworthiness are more engaged with news, more likely to pay for news, more likely to share news with friends and more likely to follow news outlets on social media (2016). These relationships between trust and revenue provide news organizations even more of an incentive to cultivate trust.

As news organizations employ strategies to rebuild trust, they must find ways to measure the effectiveness of their efforts. With the ever-growing number of sources from which people can get information, it is important to empirically investigate the relationship between trust of news organizations and quantifiable measures of usage, such as those accessible to both publishers and advertisers. Are more trusted news organizations used by more people, used more frequently and used for longer periods of time? Further, is usage of more trusted news organizations more intentional than usage of less trusted ones?

The purpose of this research was to determine whether a relationship between news media trust and usage exists. This report first reviews literature on trust and media usage, two bodies of work that help motivate the study's hypotheses involving a positive relationship between trust and usage. Based on this review, I side with the assumption that when people consume news media by creating repertoires, which are subsets of information sources people frequent. In doing so, their behavior is boundedly rational; in other words, people make decisions that are rational within reasonable limits (Simon, 1955; see Webster, 2011). 
In previous research, usage data in trust studies were collected through selfreports from participants. This study, however, measured usage by looking at passively measured data from ComScore's Internet use panel of 1 million people in the United States. Measures of audience trust were taken from a Pew Research Center study that surveyed American news consumers about news organizations they trust. As described in Chapter 3, which details the methods, both ComScore and the Pew Research Center provide representative samples of American news consumers.

While focusing on the relationship between trust and usage, the analysis, reported in Chapter 4, also explored four additional co-variates: the month for which the data was collected; whether a news source is mainstream or nonmainstream; the news source's political ideology, as classified through the primary ideology of a news organization's audience; and whether a news source is consumed on multiple platforms (i.e., not just online). The month co-variate was interacted with the independent variable of trust for all models to show differences in usage over time not explained by the explanatory variable of trust. The regression models show a positive, significant relationship between overall trust and direct traffic, but not between trust and measures of frequent usage. Adding political ideologies and multiplatform presence as control variables did not impact the relationship between trust and direct traffic. The study found evidence in one month that being a mainstream news source could moderate the relationship, but results were overall inconclusive. I conclude by discussing research and industry implications of this study, as well as suggestions for future research. 


\section{Chapter 2: Literature Review}

\section{Trust in Media Institutions}

As a general sociological concept, trust consists of a relational transaction occurring over a period of time between a trustor, or someone placing trust, and a trustee, or someone in which trust is placed (Coleman, 1990). In the context of news media, trustees are news organizations, and trustors are news consumers. This definition of trust assumes that both the trustee and the trustor have the goal of satisfying their individual interests (Coleman, 1990). Trust also operates under the assumption that neither the trustee nor the trustor will behave opportunistically, representing the readiness of one party to be vulnerable to what other parties do (see Kim et al., 2009). Trust includes expectations that the trustee is reliable and the trustor will benefit from interacting with the trustee (Coleman, 1990). In the context of news media, a news organization is expected to be reliable, and consumers are expected to benefit from interactions with news organizations.

Additional components of trust should be examined in the context of news organizations. For example, trusting news organizations involves believing in journalism as a professional practice (Liebes, 2001). Part of this professional practice involves news consumers trusting what news organizations deem as important and therefore choose to report on; journalists cannot write about all information regarding all issues, so news organizations must select which topics to cover, and how extensively (Kohring \& Matthes, 2007). This trust that news consumers have in news organizations to choose what to cover is an example of institutional trust, which refers to trust in public and 
private establishments; in the context of media trust, these establishments can be news organizations (Williams, 2012). Institutional trust is one of three types of media trust; the other two are interpersonal trust, or trust of individual news reporters, and informational trust, or trust of news content. This study focuses on institutional trust of news organizations such as The New York Times.

Historically, many scholars have examined the idea of news media trust through credibility. Some research has used credibility synonymously with trust; for example, in some of the earliest research, terms like "trustworthy" and "high credibility," as well as "untrustworthy" and "low credibility," are used interchangeably when describing sources (Hovland \& Weiss, 1951). However, a pattern emerging from the body of credibility research as a whole is that scholars have not agreed on what the core dimensions of source credibility are, thus making it difficult to define (Kiousis, 2001). In turn, newer research uses the term "trust" but draws heavily from credibility research (Kiousis, 2001; Tsfati \& Cappella, 2003, 2005). As suggested through those examples, trust and credibility are not necessarily different, mutually exclusive concepts (Self, 1996). Some even consider credibility, along with accuracy and objectivity, to be core components comprising trust (Tsfati \& Cappella, 2003). In focusing on trust instead of credibility, this study enables direct connections to be made between research in mass communication and sociological theories of trust because it draws from literature focusing on the human behavior of trust and the reasoning behind trust - not on the characteristic of credibility that is attributed to sources - in the context of mass communication (Tsfati \& Cappella, 2003). 


\section{Media Trust and Usage}

A handful of studies have associated news media trust and usage, as well as related concepts, some finding that specific factors mediate the association. For example, when Ann Williams (2012) surveyed news consumers about trust and news attention, which was segmented into categories of information and the medium through which that information is disseminated, she found the medium to make a difference. In print media the study found, after controlling for demographics, a significantly positive association between trust of newspaper reporters and attention to newspapers, but not between trust of content or trust of institutions and attention (2012). In television news the study found, after controlling for demographics, a significantly positive association between trust of institutions and attention, as well as a significantly negative association between trust of online-based news content and attention to television news, the latter of which could represent a shift in attention to online-based news content or embrace of television by people who distrust Internet content (2012). In online-based news the study found, after controlling for demographics, no association between trust of Internet news and attention (2012). This may be explained by a more critical evaluation of Internet news credibility than credibility of news distributed in traditional media, or by difficulty determining how trustworthy Internet news is (see Williams, 2012). However, one shortcoming of this study is that it did not clearly define "Internet news." The survey distributed simply asked people about any information read on the Internet, not clarifying whether "Internet news" meant, for example, information published by digitally native media outlets, such as BuzzFeed; information published by traditional media institutions with a digital presence, 
such as The New York Times or NBC; or both. Survey responses about trust of Internet news could have been different had the survey provided a more specific definition.

Other research has examined the relationship between news media skepticism and news exposure, finding the type of news organization to make a difference. When Yariv Tsfati and Joseph Cappella (2003) surveyed news consumers about skepticism, news exposure and media diets, they found skepticism to be negatively associated with exposure to mainstream news channels - defined in the study as national, local and cable television news, as well as daily newspapers — and positively associated with exposure to nonmainstream news channels, defined in this study as political talk radio shows and political information on the Internet. A follow-up study also found a negative association between skepticism and exposure to mainstream news (Tsfati \& Cappella, 2005). In terms of trust instead of skepticism, this could support a positive association between trust and exposure to mainstream news, as well as a negative association between media trust and exposure to nonmainstream news. The study also found no significant difference between skeptics' and non-skeptics' overall news consumption levels, but it did find that skeptics consumed less mainstream news and more nonmainstream news than non-skeptics (2003). In terms of trust instead of skepticism, these findings support the idea of greater consumption of mainstream news by people who trust news media more in general. Reasons for this, as Tsfati and Cappella (2003) posited in the discussion, could be that in accordance with the uses and gratifications theory, motivations that do not have to do with trust, such as social or entertainment ones, could make trust less relevant, or that there are fewer alternatives for skeptics of mainstream news. However, a major criticism of the uses and gratifications framework is 
its assumption that usage is entirely a result of individual motivations - an assumption that will be problematized more in a later section — and the Internet has made it easier for skeptics of mainstream news to access alternatives.

Another problem is using "mainstream" or "nonmainstream/alternative" as a classification. Although Tsfati \& Cappella’s (2003, 2005) studies classify news organizations according to channel and content, there is no universal agreement on which characteristics classify a news organization as mainstream or nonmainstream. What makes a news organization mainstream or nonmainstream can be difficult to define, particularly because something considered nonmainstream in one time and place could be labeled as mainstream in another (Dowmunt \& Coyer, 2007). Alternative news organizations can offer social critique, challenge power structures, share radical viewpoints and advocate for change, among other characteristics, with more of a focus on analysis than general reporting; mainstream media organizations can be fairly conventional and formulaic with more of a focus on reporting (see Kenix, 2012). Some even argue that mainstream and nonmainstream news organizations are on a spectrum, with some mainstream news organizations exhibiting some nonmainstream characteristics, and vice versa (Kenix, 2012). For the purpose of this study, nonmainstream news organizations refer to those which might focus more on analysis and opinions, and mainstream news organizations refer to ones that produce more formulaic reporting, in the context of the news media landscape from early 2014 to mid2015. Any different definitions used in previous studies are articulated.

Yet other research has looked at relationships between news media skepticism and exposure to online news specifically. A two-part study by Yariv Tsfati asked 
participants about trust and consumption of "Internet news sites and online bulletin boards containing news information" in general - a more specific definition than the one offered in Williams' (2012) study but still a vague one — as well as trust and consumption of 11 specific Israeli news websites, some mainstream and some nonmainstream (2010). Both parts of Tsfati's study (2010) found a significant and negative association between exposure to online news in general and skepticism. These findings support a positive relationship between trust and general news media use. When incorporating the mediator of mainstream versus nonmainstream, both parts of the study found a negative correlation between exposure to mainstream online news and skepticism, and only the second part of the study found a positive relationship between skepticism of mainstream news and usage of nonmainstream news (2010). These findings suggest that the type of news impacts the relationship between trust and exposure. The inconsistencies related to type of news, specifically nonmainstream exposure, between the parts of this study could stem from differences in data collection and participant recruitment (2010). In the first part, people were interviewed by telephone, and there were relatively few nonmainstream news consumers represented (2010). In the second part, participants self-selected to participate when already browsing one of four news websites, three of which were nonmainstream, leading to an overrepresentation of nonmainstream news consumers in the second part (2010). Revisiting this question with a consistent and more representative participant sample could help clarify inconsistencies. A principal limitation of the studies just reviewed is their heavy reliance on the assumption that news media usage is an outcome of individual motivations, as the uses and gratifications theory assumes. This theory has been criticized by scholars for several 
reasons. One concern is with the bias researchers have in identifying gratifications without the input of subjects, which could result in an overestimation of operative gratifications (Lometti et al., 1977). A second concern is when subjects identified gratifications in early research, they did so by associating them with channels, allowing for the possibility of mixing these two concepts and overestimating total gratifications (1977). A third, which perhaps has the greatest implications in the context of this study, is the assumption that the audience is always active in selecting what information to consume (Blumler, 1979). In reality, news consumers can be completely active, completely passive or somewhere in between, complicating the concept of news media usage (Blumler, 1979). Relying on the assumption that people actively choose all news they consume, as the uses and gratifications theory does, is problematic because such assumptions could overemphasize the relationship between the news people trust and the news people consume. For example, if people do not actively choose every news organization from which they read content, they may use news organizations they do not trust. The latter may be due to incidental exposure or purely out of habit. When passively consuming news, people may not remember using news organizations they do not trust as much as news organizations they do trust. In the self-reported data collection utilized by all of these studies, people may report using news organizations they do trust more than news organizations they do not trust, or using news organizations they trust more in general, resulting in a reporting bias. Incorporating passively consumed news into research examining the relationship between trust and usage would reduce these reporting biases and errors. The following section examines components of news selection that account for and help explain news media choice in more detail. 


\section{Complications of News Media Choice}

Most of the research reviewed aligns with the paradigm of rational choice theories, which posit that people act rationally when reviewing options to make decisions; that people seek positive outcomes and not negative ones; and that people want to find the most accurate, trustworthy information possible to consider when making these decisions (Lupia \& McCubbins, 1998; Tsfati \& Cappella, 2003). This paradigm also assumes that people cannot process all stimuli, so they focus on specific ones when they see that the benefits of processing that information greatly outweigh the costs of it (Lupia \& McCubbins, 1998). This is a logical theory to apply to news because news consumers, especially in today's high-choice environment, cannot give everything attention and thus must decide which news to consume.

In the news media context, rational choice results in people making choices that reflect patterns of selective exposure and selective avoidance of information (Tsfati, 2010). Selective exposure is evidenced when people favor or seek out information or information sources that reinforce their existing beliefs (various, as cited by Tsfati, 2010). Selective avoidance, which does not necessarily accompany selective exposure, is seen when people purposefully avoid information that does not confirm their existing beliefs (Garrett, 2006a, 2006b). Patterns of selective exposure and selective avoidance can be considered instances of people making rational decisions about which news source to choose based on their ideological predispositions, as well as avoiding cognitive dissonance based on consumption of counterintuitive information.

Studies have shown evidence of partisan selective exposure. For example, Stroud's (2008) study of 2004 United States election coverage suggests that news 
consumers' political beliefs predicted which talk radio shows, cable news channels and websites they chose to use. Another study found that news consumers are more likely to choose to consume - and spend more time consuming — information that reinforces their political beliefs, and slightly though significantly avoid information that challenges their preexisting beliefs (Garrett, 2009). A third study suggesting political views influence exposure to cable news sources also found that political views impact news consumers' impressions of them; when people use news sources that are thought to align more with their political views, they are less likely to think these sources are biased and more likely to think the content is interesting and informative (Coe et al., 2008). If people think some news sources are less biased than others because of alignment with political views, and if they like the content, they could be more likely to use those news sources even if they don't particularly express trust for that source. Consequently, when seen in the aggregate, such news sources may have more regular usage than non-partisan sources when controlling for trust.

The rational choice paradigm has guided much of uses and gratifications research (Gurtewich, Blumer \& Katz, 1973) as well as economic theories of program choice (Wildman \& Owen, 1992). Extant work associating news media trust and usage makes similar assumptions, often also drawing on uses and gratifications research.

Although the rational choice theory offers an explanation of news media choice, there is a limit to how rational decisions can be. Bounded rationality posits that people make rational decisions within reasonable limits because people cannot possibly consider every potential outcome of a decision and thus make decisions that are entirely reasoned and purely rational (Simon, 1955). Bounded rationality also provides a lens through 
which other news consumption behavior can be explained. In today's news environment, people often don't have enough time to consider every possible outcome of news choices. Finite time results in satisficing, or making a decision upon finding an option that meets certain criteria instead of exhausting all options to find the best possible option (Newell \& Simon, 1972). When people evaluate subjective criteria in the context of news, subjective qualities assessed are features of news organizations' products that become significant when people choose to pay attention to that particular product (Wolling, 2009). Trustworthiness is one such quality that could influence news usage.

Compatible with the idea of news consumers using bounded rationality is a structurational perspective on media choice. The theory of structuration emphasizes the duality of thought subjectivism, which is the belief that behavior is caused by individuals exercising free will, and thought objectivism, which is the belief that behavior is caused by large structures such as social institutions (Giddens, 1984). Studies rooted in this perspective consistently show that despite all the choice and autonomy digital news organizations provide, many enduring aspects of people's social lives (structures) such as habits, routines, language and geography explain people's choices as much or even to a greater extent than their preferences do (Webster, 2014). In this context, the news media environment is created and altered by interactions between news consumers and news organizations, the latter of which relies on usage measures to determine consumption patterns (Webster \& Ksiazek, 2012).

News Media Repertoires. Repertoires refer to smaller groups of favored news organizations that people regularly consume (see Webster, 2011). Early research in this area, which focused on television channel repertoires, found a person's access to cable 
television and time spent watching television to be two structural factors that predicted repertoires (see Taneja et al., 2012). However, with today's news consumption behavior, it is important to look at how repertoires are formed across multiple platforms. One such early study, conducted in 1996, found that repertoires are formed around interest areas, such as sports, when people are asked to choose from a preset list of repertoires (Reagan, 1996). Later research, which examined usage to determine repertoires, found that repertoires reflected a combination of medium and content preferences, some of which were found to be common among people of the same age, education level or socioeconomic status (see Taneja et al., 2012). For repertoires of online news organizations specifically, research has shown that consumption starts with choosing the Internet as the medium, then continues with a search for content to fulfill needs; when looking for daily news and hard news online, people typically search for similar content and use a traditional repertoire of traditional news organizations for this content (Kim, 2016). In general, the literature shows that even for digital news organizations, both individual characteristics and structural factors explain people's repertoires (e.g., Taneja et al, 2012). Repeatedly consuming information from the same news organizations may reflect more passive, habitual consumption experiences because news consumers are not making new rational decisions to evaluate these sources. Although news organizations cannot measure individual repertoires specifically using aggregated audience measurement data, they can passively measure some reasonable proxies such as "repeat usage" through measures of frequency, such as the average number of days a user visits a website in a designated time period, and measures of time spent on a website. 


\section{Research Questions and Hypothesis}

The literature detailed in the previous sections suggests that news consumers are rational, making decisions about what information to consume or avoid based on reasonable limits within rationality. To ease decision-making when choosing among an abundance of options, people form repertoires, or smaller sets of options that they frequently visit and choose from. This allows for more passive news consumption because people have already evaluated this smaller subset of news organizations. Trust can be a factor in both rationally choosing a news organization and including it in a repertoire. Studies about relationships between trust and usage — and related concepts such as credibility, skepticism and exposure — suggest relationships exist between how much news consumers trust news and how often they consume it. It is moot and difficult to determine which came first: whether people's trust in a news organization causes them to use it repeatedly, or whether people end up trusting a news organization they use repeatedly. Either way, a positive relationship between trust and regular usage of a news organization would be expected and has been suggested in previous research. Despite its virtues, the literature reviewed has several other limitations summarized as follows, some of which I have already alluded to in earlier sections.

First, a major limitation of the literature reviewed above is the way usage and exposure are measured. News consumers in most of those studies were surveyed or interviewed about their news media usage. Active self-reports of usage could have resulted in inaccurate estimates; people could have overestimated, underestimated or misremembered the amount of time they spent online, spent consuming news in general or spent consuming news from a specific organization. People could have been more 
likely to self-report higher usage of news organizations they trust, or that are more trusted overall. Self-reports also could have resulted in inconsistent data when the phrasing of questions allowed for interpretation. For example, Williams' survey about trust and attention asked respondents to rate how much attention they give to certain types of news on a Likert scale, with 1 meaning "little attention" and 10 meaning "very close attention" (2012). These definitions are relative; "little attention" could mean different amounts of time to different respondents, which could have resulted in people selecting different responses for the same amount of time. One of Tsfati's (2010) studies passively tracked the total time participants spent reading online news but did not segment time spent into news organizations. Because the study collected data about mainstream and nonmainstream news, found to mediate the relationship between trust and usage, and did not segment time into individual news organizations, this passive measurement cannot be segmented to account for this difference.

A second limitation is the literature's dependence of news media choice on individual motivations, citing theories such as uses and gratifications. Critiques of this theory include researcher bias in identifying gratifications, associations between gratifications and channels, and the assumption that audiences actively consume news, implying that usage is an outcome of individual motivations (Lometti et al., 1977;

Blumler, 1979). These and other concerns leave room for error in uses-and-gratificationsbased research, including the absence of passive news consumption.

A third limitation is the use of similar but not entirely identical concepts to trust and usage. For example, although credibility is similar to trust, additional factors can influence trust of news, so results could differ when looking at all components of trust. 
Another example involves substituting skepticism for distrust. Negative associations between skepticism and usage might not automatically imply a positive association between trust and usage.

A fourth limitation is the focus of some research on traditional news platforms, such as newspapers and television. These types of news platforms provide a limited amount of options for consumers to choose from, which, as Tsfati and Cappella posit, might lead people who are skeptical of news to use mainstream news organizations because there are few or no alternatives (2003). This complicates the relationship between usage and trust because people might consume news that they don't trust because they think it's the only option. However, because the Internet provides many more options for consumers than traditional news platforms do, skeptics have more alternatives to mainstream news organizations from which they can choose. This further complicates the relationship between usage and trust because having these additional options could enable people to choose them over mainstream news organizations, which could shift regular usage of mainstream news organizations to these alternative sources and eventually impact trust. The next section explains how this study has overcome these limitations.

Most significantly, since previous studies were conducted, the news environment has experienced even more fragmentation and autonomy by its consumers (see Taneja et al., 2012). Partly because of the lower barrier to entry on the Internet than on traditional platforms such as television, new online sources of news and information are created all the time, giving consumers increasingly more choices than ever before. News consumers have greater access to these online sources, which are primarily free to consumers and 
available anywhere, than they did with news organizations that distribute content through traditional platforms, often geographically limited in reach and to which consumers often received access through a paid subscription service. People also access information in different ways, increasingly relying on curated distribution models, such as social network feeds and search engine results pages, to surface options for information consumption. Increased choice of and access to information, as well as changes in information distribution, have the potential to change or expand news consumers' repertoires, which could lessen loyalty to some news organizations as attention is shifted toward others. Conducting this study at a time that reflects these changes to the news environment could yield different results in usage relationships than the literature reviewed. For example, because news consumers have more choices, they could shift attention to other news organizations, or they could access information from a news organization because it showed up on a search engine results page or in their Facebook News Feed. The next section explains how this study overcomes these limitations.

In summary, the objective of this study is to determine whether the trustworthiness of news organizations, as determined through percentages of a representative sample who trust them, is associated with usage. This leads to the following broad question:

RQ1: Does trustworthiness of a news organization correlate with its frequent usage?

The literature provides theoretical framework to explain trust, news media choice and the formation of repertoires, or groups of news organizations frequently used by consumers. Previous research has associated repertoires with the frequency of visiting a 
website and the amount of time spent on a website. One can use the ideas of repertoires and selective exposure to help explain direct traffic, or why people choose to visit a website directly instead of being referred to it through a third party, such as a social network. This leads to the following hypothesis:

H1: The trustworthiness of a news organization is positively correlated with its usage, as measured through average usage days, average minutes per visitor and direct traffic.

Previous research about skepticism and news exposure, which found a negative association between skepticism and mainstream news usage and positive association between skepticism and nonmainstream news usage, supports the idea that usage patterns could be different for mainstream and nonmainstream news organizations. It also could support the idea that trust and mainstream news usage could be positively associated, whereas trust and nonmainstream news usage could be negatively associated. Previous research about partisan selective exposure discussed also supports ideas that usage patterns could be different for sources with different political ideologies, and differences in previous studies about trust and usage discussed support ideas that relationships could differ between sources that publish on multiple platforms and those publishing online only. This leads to a further question:

RQ2: Does being a mainstream news source, having an affiliation with a political ideology or being a multiplatform news source moderate this relationship? 


\section{Chapter 3: Methods}

This study examined associations between overall trustworthiness of news organizations and measures of usage. The unit of analysis for trustworthiness is the news organization, with percentages coming from how many people in Pew's representative sample who have heard of a news organization indicated they trusted it. To measure usage, the study looked at measures that represent behavior associated with repertoires and repeat usage of news organizations' websites: how often people use a website, how long people use a website, and how many people visit the website at the beginning of an Internet session, an indicator of direct traffic, rather than through a referral. Instead of asking news consumers about usage, which results in subjective answers that could be inaccurate or misremembered, I relied on usage data passively collected from news organization website visits to get exact measures. The measures of average usage days per month per visitor of a news organization's website, the average minutes per visitor per month for a news organization's website, and the percentage of direct traffic to a news organization's website offer insights into relationships between trustworthiness of news organizations and frequent, lengthy and intentional use, respectively, of their websites.

This study incorporated four covariates. Because previous research has found that behavior may differ based on the type of news organization, this study examined whether being mainstream or nonmainstream moderates the relationship between trust and usage. For the purpose of this study, mainstream news organizations are broadly classified as larger entities producing more formulaic reporting, and nonmainstream news 
organizations are broadly classified as smaller ones providing more analysis, with other potential differences (see Kenix, 2012). Another covariate was the month in which the usage measures are taken. This is because certain events leading to surges in major news stories or seasons such as the winter holiday months, during which many people may take time off, have the potential to impact news consumption. A third was the primary political ideology of a news organization's audience - whether its news consumers lean politically left, politically right or are fairly neutral. I derived these classifications from data in the Pew Research Center's "Polarization and Media Habits" report (2014). A fourth was whether a news source has a presence on another platform, such as television, or whether it is only available online.

\section{Sample}

This study measured trust and usage using secondary data collected using samples representative of news consumers in the United States. For the same set of news organizations, data from the Pew Research Center and ComScore are comparable in terms of their audiences because they both have large, representative samples. Both sources are described in more detail below.

Pew Research Center. I measured trust using information shared in the Pew Research Center's "Polarization and Media Habits" report, which among other questions asked news consumers whether they trusted government and political news from 36 news organizations (Mitchell et al., 2014). The report was one part in a series that looked at the scope and nature of political polarization in the United States, as well as relationships between political polarization and society, the government and personal lives (2014). The Pew Research Center, a nonpartisan fact tank, conducts empirical social science research 
to learn about American and international attitudes, trends and issues (Pew Research Center, n.d.). The center is a subsidiary of The Pew Charitable Trusts, an independent, nonpartisan, non-governmental nonprofit that focuses on global research and public policy (The Pew Charitable Trusts, n.d.). This data was chosen because it is a representative sample of U.S. news consumers, includes a representative sample of news organizations, and was collected by a nonpartisan organization.

ComScore. I tracked usage through ComScore's Media Metrix, analytics that track Internet consumption and demographic data. ComScore measures brands, audiences and consumer behavior across platforms worldwide (ComScore, n.d.). I used this data because it is a large, representative sample of American Internet users and collects data from a large number of websites, some of which are news organizations.

\section{Time Frame}

The Pew Research Center conducted its study from March 19 to April 29, 2014. I used ComScore reports of 35 news organizations' usage for three months: October 2014, December 2014 and July 2015. ComScore data were available for all three months, and the selected months account for potential variations in usage. October does not include major religious holidays or heavy travel seasons, whereas December includes major religious holidays and July is a common month for travel. In the few months between when Pew's study was conducted and when ComScore data were collected, some audience trust levels could have changed for specific news sources if some of the people surveyed had, for example, experiences with bias or inaccuracy of specific sources (Media Insight Project, 2016). However, it likely would not have changed significantly, 
supported by no change in overall news media trust from Gallup between 2014 and 2015 (Swift, 2016).

\section{Data Collection}

Pew Research Center. In its 2014 report, the Pew Research Center used survey responses collected between March 19 and April 29, 2014 from 2,901 Internet users who are part of its American Trends Panel (Mitchell et al., 2014). Members of the panel were recruited from the nationally representative Political Polarization and Typology Survey, which surveyed more than 10,000 Americans by phone between January 23 and March 16, 2014 (2014). Among the 4,753 Internet users who are part of the panel, 61 percent, or 2,901 people, responded to its first wave, from which data was used for the Pew Research Center's report (2014). I chose to use data from this study because of its vast and varied selection of news organizations and its large, representative sample population.

Survey respondents who use the Internet were asked to select all news organizations they had heard of from a list of 36: CNN, ABC News, CBS News, NBC News, Fox News Cable Channel, USA Today, MSNBC, PBS, The New York Times, The Wall Street Journal, Yahoo News, The Washington Post, the BBC, Google News, The Rush Limbaugh Show, The Huffington Post, The New Yorker, The Daily Show, The Colbert Report, Bloomberg, NPR, The Glenn Beck Program, The Sean Hannity Show, Al Jazeera America, The Guardian, The Economist, Drudge Report, Politico, BuzzFeed, Mother Jones, Slate, The Blaze, The Ed Schultz Show, Breitbart, Daily Kos and ThinkProgress (2014). Respondents were then asked which of the sources they knew about that they generally trusted regarding government and political news, and which of the sources they knew about that they generally distrusted regarding government and 
political news (2014). Of these 36 news organizations, The Sean Hannity Show was excluded from this study because ComScore did not collect data from its website during the time periods used.

I obtained trustworthiness percentages from multiple static and interactive infographics showing percentages of overall participants, as well as percentages of participants by political ideology, who trust news organizations included in the "Political Polarization and Media Habits" report. These infographics include the percentages of panelists who trust, distrust, neither trust nor distrust, and have not heard of each of the 35 news organizations. Because this study focused on the relationship between trust and usage, and people likely would not have used news sources they had not heard of, I adjusted percentages from the Pew Research Center report to reflect trust, distrust and neither trust nor distrust out of the people who had heard of a particular news organization, and not out of the study's entire sample population.

The Pew Research Center determined respondents' political ideologies using a 10-question scale that asks how respondents view an array of issues, with each position having a traditionally conservative or liberal association, that the center has been using in research since 1994 (Mitchell et al, 2014). The proportion of traditionally liberal views to traditionally conservative views determines the political ideology and degree of affiliation: consistently liberal, mostly liberal, ideologically mixed, mostly conservative, or consistently conservative. Note that because the political ideologies are measured and not self-reported, some respondents' self-identified political ideologies may not match the measured ones in this report. 
To simplify the Pew Research Center's political ideology classifications, I combined percentages from "consistently liberal" and "mostly liberal" respondents to form measures from "liberal" respondents, and from "consistently conservative" and "mostly conservative" to form measures from "conservative" respondents. The equations that use proportions to calculate these combined percentages can be found in Appendix A. As with the overall percentages, I then adjusted these percentages to be only out of people who had heard of a news organization.

ComScore. To collect Media Metrix data, ComScore uses Unified Digital Measurement methodology. This methodology combines usage data specific to people, collected through software meters on selected panelists' computers, and usage data specific to websites, collected through tracking pixels on websites and other online content assets (ComScore, 2013). ComScore reports usage data for more than 250,000 digital properties and more than 2 million people worldwide (ComScore, n.d.; ComScore, n.d.). I used this data in this study because of its large, representative sample population and measurement of hundreds of thousands of digital properties.

I collected ComScore data for the 35 news sources using two data reports. I ran Key Measures reports for each month to obtain the average usage days per visitor and average minutes per visitor for each website. Average usage days per visitor refers to the average number of days per month that people visited a website, and average minutes per visitor refers to the average amount of time visitors spent on a website each month. I ran Source/Loss reports for each month to determine direct traffic to a website. This is listed as the "\% of Entries" for the "Logon" source of incoming traffic. "Logon" refers to when a page is the first to load in a browser during a session; however, it also includes the first 
page in a session that extends two days (i.e., goes past midnight), the first page visited after 30 minutes of inactivity, and the first page accessed from a link in a document or email (ComScore, n.d.).

Usage data from July 2015 for The Colbert Report and The Ed Schultz Show were incomplete because both shows ceased airing that month; thus, I excluded these two data entries from the study, reducing the sample size to 103 from 105.

\section{Rigor}

Both of these secondary data sources are reliable. Although trust may change over time, it would likely not change overnight, so participants in the Pew Research Center study would likely have given the same answer on average had they been surveyed on a different day in that time period. All ComScore usage data is measured passively through tracking, so it measures exact usage of the time period measured. Both tools also are valid. The Pew Research Center study weighted the responses using a multi-step process (Mitchell et al., 2014). For all Pew Research Center study respondents, the error attributable to sampling expected at the confidence level of 95 percent is plus or minus 2.3 percentage points (2014). Because ComScore tracks usage through both individuals and websites, it can validate that the activity that the website tags is measuring is consistent with the methodology it uses for audience measurement (ComScore, n.d.).

\section{Analysis}

This study used multiple regression to develop models for predicting the relationship between trust and usage, as well as how other variables moderated this relationship. Multiple regression was used because it enables one variable to be predicted from multiple others (Cronk, 2012). 
Dependent and Independent Variables. The two dependent variables were the frequency, classified as the average usage days per visitor multiplied by the average minutes per visitor, and percentage of direct traffic to a website, as measured using ComScore data from October 2014, December 2014 and July 2015. Average usage days were measured as the average number of days, rounded to the tenth decimal place, that each visitor has gone to the website. Average minutes per visitor were measured as the average number of minutes, rounded to the tenth decimal place, that people have used the website during that month. Average usage days and minutes have a high and positive, or collinear, correlation, so it would be statistically redundant to include both separately; therefore, I multiplied these two usage measures to form one "frequency" variable. Direct traffic to a website was measured as the percentage of "Logon" visits to a website. The primary independent variables in this study were trust of a news source, measured as the overall percentage of the Pew study's respondents who have heard of and trust a news organization, interacted with one of three months.

Moderating Variables. Mainstream. Whether a news organization is mainstream or nonmainstream was one of three moderating variables. This categorical variable was coded using " 1 " and " 0, , " 1 " meaning the media outlet is considered mainstream and " 0 " meaning it is not considered mainstream, so it is therefore considered nonmainstream. For the purpose of this study, mainstream news organizations were defined as larger news organizations that offer conventional content (see Kenix, 2012). The following news organizations were coded as mainstream: The Economist, the BBC, NPR, PBS, The Wall Street Journal, ABC News, CBS News, NBC News, CNN, USA Today, The New York Times, The Washington Post, MSNBC, The Guardian, The New Yorker, 
Google News, Yahoo News, The Huffington Post, Bloomberg, Politico, BuzzFeed, Fox News and Al Jazeera America.

For the purpose of this study, nonmainstream news organizations were defined as smaller news organizations offering more analysis than straight reporting, including content that might critique social or power structures or advocate for change, in the context of the news media environment from 2014 to mid-2015 (see Kenix, 2012). The following news organizations were coded as nonmainstream: The Blaze, Mother Jones, Slate, Breitbart, ThinkProgress, Drudge Report, Daily Kos, The Glenn Beck Program, The Daily Show, The Colbert Report, The Ed Schultz Show and The Rush Limbaugh Show.

Political ideology. A second moderating variable was political ideology, as determined by the primary ideology of each news source's consumers. It can be difficult to assign political ideologies to news media outlets, and previous research discussed supporting the concept of partisan selective exposure supports this decision of using audience ideologies. The Pew Research Center study asked respondents to self-report which news sources they used in a typical week, then segmented usage percentages by political ideology to show the ideological makeup of consumers for 31 of the news sources included in the survey (Mitchell et al., 2014). To simplify political ideologies for the purpose of this study, I combined the percentages of "consistently liberal" and "mostly liberal" consumers to determine the percentage of "liberal" consumers, and the percentages of "consistently conservative" and "mostly conservative" consumers to determine the percentage of "conservative" consumers. 
Four news sources were not included in the Pew Research Center report's audience ideology report because their sample sizes were too small to analyze: ThinkProgress, Daily Kos, Mother Jones and The Ed Schultz Show (Mitchell et al., 2014). Instead of excluding these news sources from the political ideology analysis entirely, I replicated percentages for each political ideology from news sources with similar news values and overlapping audiences (from comScore) much greater than one would expect by chance alone (see Webster \& Ksiazek, 2012). To do this, I ran Cross-Visiting ComScore reports for each month to determine the shared audience members among these four news sources and similar ones. I used percentages of overall Internet users that used either of these news sources to calculate the expected number of shared audience members between the four news sources and comparable ones, which I then compared to the actual number of shared audience members found in the Cross-Visiting reports. These pairs had many more actual shared users than expected. Thus, based on their similar liberal dispositions, predominant online presence and much greater audience overlap than expected based on chance alone, I applied the ideological audience composition of Slate's users to ThinkProgress, Daily Kos and Mother Jones. Likewise, I applied MSNBC's composition to The Ed Schultz Show because the latter airs on MSNBC. Appendix B shows these calculations.

To be moderating variables, these ideologies were then coded as binary variables in accordance with the highest percentage of news sources' audience members. Thus, I coded the following news sources as liberal: Al Jazeera America, the BBC, BuzzFeed, The Colbert Report, Daily Kos, The Daily Show, The Economist, The Ed Schultz Show, The Guardian, The Huffington Post, Mother Jones, MSNBC, The New York Times, The 
New Yorker, NPR, PBS, Politico, Slate, ThinkProgress, and The Washington Post. I coded the following news sources as conservative: The Blaze, Breitbart, Drudge Report, Fox News, The Glenn Beck Program, and The Rush Limbaugh Show. I coded the following news sources as mixed: ABC News, Bloomberg, CBS News, CNN, Google News, NBC News, USA Today, The Wall Street Journal, and Yahoo News.

Multiplatform presence. A third binary variable was whether a news source has a presence on another platform (e.g., television) or whether it is only available online. I coded the following news sources as " 1 ," or having a presence on another platform: Fox News, The Glenn Beck Program, The Rush Limbaugh Show, The Blaze, Al Jazeera America, the BBC, The Economist, The Guardian, MSNBC, NPR, The New York Times, The New Yorker, Politico, The Washington Post, The Daily Show, The Colbert Report, The Ed Schultz Show, ABC News, Bloomberg, CBS News, CNN, NBC News, USA Today and The Wall Street Journal. I coded the following news sources as "0," or being online-only: Breitbart, Drudge Report, BuzzFeed, The Huffington Post, Slate, Google News and Yahoo News. 


\section{Chapter 4: Analysis}

I ran a series of regression analyses using pooled cross-sectional data. I chose multiple regression analysis because it can predict one dependent variable from more than one independent variable, explicitly controlling for multiple factors that might impact the dependent variable; this is especially powerful when relying on nonexperimental data such as the secondary data used in this study (Wooldridge, 2012). I organized the cross-sectional data so that the three time periods for each media outlet were adjacent — with three records for each media outlet, each month coded as a dummy variable — therefore making it possible to conduct a pooled cross-sectional analysis (Wooldridge, 2012). I employed pooled cross-sectional data because they allow for intercepts and slopes to change over time, reflecting differences in distribution in the independent usage samples taken at three different points in time (2012). Using panel data, while similar in its inclusion of cross-sectional and time series dimensions, would require following the same individuals over time, which was not possible given the anonymity of ComScore data and different Internet audience sizes from month to month (2012).

Because of collinear usage measures, regressions to answer this research question used one of two dependent variables: direct traffic (reported as a percentage to the thousandths place) or frequency, a variable comprising the product of the number of usage days per visitor and the average minutes per visitor (both reported as decimals to the thousandths place). Because I analyzed multiple dependent variables, I calculated pairwise correlations among the three usage measures before running regressions. I 
combined average usage days per visitor and average minutes per visitor to form one "frequency" variable because of their high collinearity, as shown in Table 1.

Table 1

Correlation Matrix Between Dependent Variables

\begin{tabular}{lccc}
\hline & $\begin{array}{c}\text { Average Usage Days } \\
\text { per Visitor }\end{array}$ & $\begin{array}{c}\text { Average Minutes } \\
\text { per Visitor }\end{array}$ & $\begin{array}{c}\text { Percentage of } \\
\text { Direct Traffic }\end{array}$ \\
$\begin{array}{l}\text { Average Usage Days } \\
\text { per Visitor }\end{array}$ & 1 & $0.84 * * *$ & 0.11 \\
$\begin{array}{l}\text { Average Minutes } \\
\text { per Visitor }\end{array}$ & $0.84 * * *$ & 1 & 0.08 \\
$\begin{array}{l}\text { Percentage } \\
\text { of Direct Traffic }\end{array}$ & 0.11 & 0.08 & 1 \\
\hline Note: $* * * p<.001$ & & &
\end{tabular}

Because the frequency variable is significantly skewed to the right, as shown in the histogram in Figure 2, I used the logarithm of the frequency variable in these regression analyses to create a more normal distribution (Benoit, 2011).

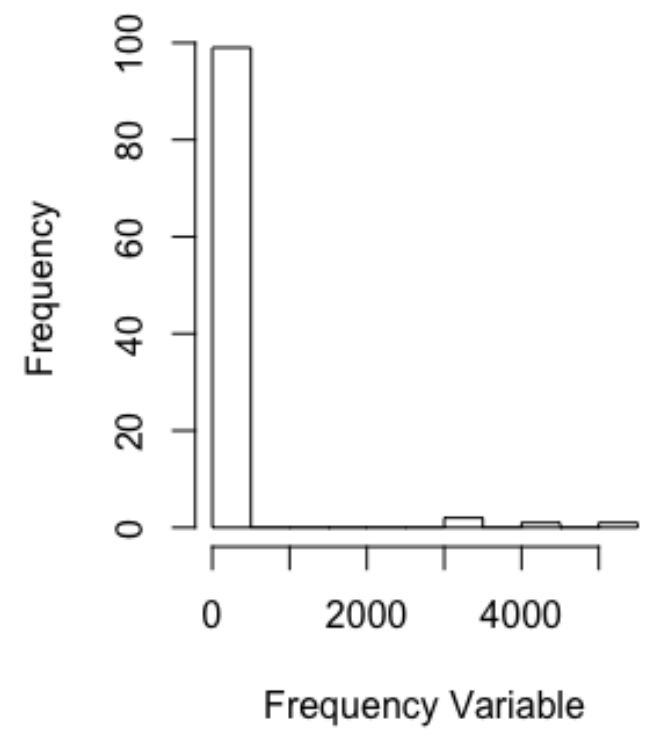

Figure 2. Histogram of frequency variable 
As shown in Figure 3, which shows the histogram of the logarithm of the frequency variable, the logarithm of the frequency variable has a more normal distribution than the frequency variable in regular form.

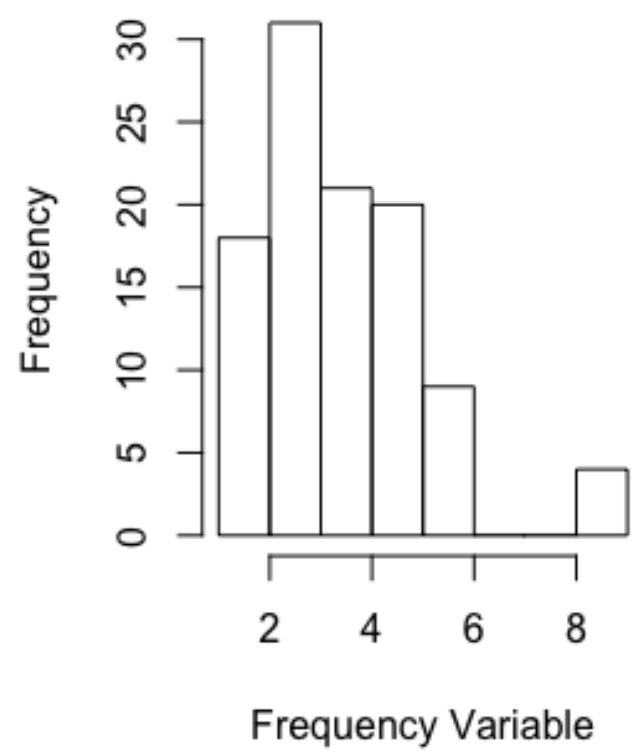

Figure 3. Histogram of Logarithm of Frequency Variable

The independent variables used in these regression analyses are the percentages of trustworthiness of each news source, adjusted to be derived from only those who have heard of that news source, interacted with binary variables for the three months in which the data were collected: October 2014, December 2014 and July 2015. I included the months as binary variables so that the analysis could show changes in the dependent usage variables over time that were not caused by the explanatory variable of trustworthiness. The time-constant variable of trustworthiness was interacted with each of the dummy month variables to create three trust-month variables: trustworthiness $*$ October, trustworthiness * December, and trustworthiness * July. In a fixed effects model such as this one, time-constant variables such as trust cannot be by themselves but 
can be interacted with dummy variables for years to see how usage has changed over time (Wooldridge, 2012).

\section{Correlation between trustworthiness of a news organization and frequent usage}

Table 4 reports the results of the first model, in which I ran a regression to predict the frequency people used a news source based on how trustworthy the news source is, incorporating interactions with months. The regression equation was not significant $(\mathrm{F}(3,99)=0.7323, \mathrm{p}>.05)$ with an $\mathrm{R}^{2}$ of 0.02171 . Trustworthiness, when interacted with month variables, is not a significant predictor of frequent use. This answers RQ1, which asks whether trustworthiness correlates with frequent usage. This also does not support part of H1, which hypothesizes trustworthiness will be positively correlated with frequency. Because this initial relationship is not significant, I did not build further regressions with moderating variables.

Table 4

Regression Model to Explain Trustworthiness and Frequent Usage

\begin{tabular}{lccc} 
Variable & Estimate & Standard Error & $\underline{\operatorname{Pr}(>|t|)}$ \\
(Intercept) & 2.94483 & 0.40189 & $6.42^{\mathrm{e}-11 * * *}$ \\
Trust * October & 0.01251 & 0.01335 & 0.351 \\
Trust* December & 0.01193 & 0.01335 & 0.143 \\
Trust * July & 0.01959 & 0.01326 & 0.374 \\
\hline
\end{tabular}

${ }^{a} N=103 .{ }^{\mathrm{b}}$ Multiple $R^{2}=0.02171 .{ }^{\mathrm{c}}$ Adjusted $R^{2}=-0.007937 .{ }^{\mathrm{d}} * * * p<.001$.

\section{Correlation between trustworthiness of a news organization and direct traffic}

Table 5 reports the results of the regression models testing the relationships between trustworthiness and direct traffic, as well as moderating and control variables. Instead of testing all variables at once, I incrementally included variables to build a models series in which I could control fixed effects. 
In the first model, I ran a regression to predict the percentage of news source users who visit a website directly based on the trustworthiness of the news source, incorporating interactions with months. I found significant regression coefficients for all three months $(\mathrm{F}(3,99)=8.595, \mathrm{p}<.05)$ with an $\mathrm{R}^{2}$ of 0.2066 . The predicted direct traffic percentage expressed as a regression equation is equal to [3.49528 $-0.04391($ OCT $)+$ $0.05874(\mathrm{DEC})+0.10185(\mathrm{JUL})]$, where OCT is the interaction between trustworthiness, a percentage, and October, a binary variable; DEC is the interaction between trustworthiness, a percentage, and December, a binary variable; and JUL is the interaction between trustworthiness, a percentage, and July, a binary variable. Based on these predictions, direct traffic increased by $0.04391 \%$ in October, $0.05874 \%$ in December, and $0.10185 \%$ in July for each percentage of trustworthiness. OCT, DEC and JUL were significant predictors, all positively correlated with direct traffic. This supports part of H1, which hypothesizes that trustworthiness will be positively correlated with direct traffic.

In the second model, I ran a regression to predict the percentage of news consumers who visit a website directly based on the trustworthiness of the news source, interacted with months, then incorporating binary control variables for political ideology (with ideologically mixed as the reference) and multiplatform presence. All three trustmonth coefficients are significant, consistent with the initial regression; the conservative ideology variable is slightly significant; and the liberal ideology and multiplatform variables are not significant $(F(6,96)=4.981, \mathrm{p}<.1)$ with an $\mathrm{R}^{2}$ of 0.2374 . Although the conservative ideology variable is slightly significant, the significance of the relationship 
between trustworthiness and direct traffic does not change when controlling for political ideology and multiplatform presence.

In the third model, I ran a regression to predict the percentage of news consumers who visit a website directly based on the trustworthiness of the news source, interacted with months and a mainstream news binary variable, with control variables for political ideology and multiplatform presence. A regression between direct traffic and mainstream news was not significant $(F(1,101)=1.49, \mathrm{p}>.05)$ with an $\mathrm{R}^{2}$ of 0.01454 ; thus, only its interactions were considered, and it wasn't included by itself. In the third model, the trust-month coefficient for July is positive and slightly significant, and the conservative ideology variable is significant, with all other variables insignificant $(F(9,93)=3.663, p<$ .1) with an $R^{2}$ of 0.2617 . The variance inflation factors of the mainstream interactions with the trust-month variables and the control variables, ranging from 1.278262 to 8.037816, show that no serious multicollinearity issues were encountered. Thus, trustworthiness matters more for a source being mainstream than for a nonmainstream source only in July, but the difference is insignificant in other months. 
Table 5

Regression Models to Explain Trustworthiness and Direct Traffic

\begin{tabular}{|c|c|c|c|c|c|c|}
\hline & Beta (1) & $\underline{\mathrm{T}}$ & Beta (2) & $\underline{\mathrm{T}}$ & $\underline{\text { Beta (3) }}$ & $\underline{\mathrm{T}}$ \\
\hline Trust $*$ Oct & $\overline{0.04391}$ & $2.0 \overline{7} 2 *$ & $\overline{0.05942}$ & $2.3 \overline{8} 3 *$ & 0.012306 & $0 . \overline{256}$ \\
\hline Trust * Dec & 0.05874 & $2.772 * *$ & 0.07425 & $2.383 * *$ & 0.007397 & 0.154 \\
\hline Trust $*$ Jul & 0.10185 & $4.839 * * *$ & 0.11705 & $2.978 * * *$ & 0.095608 & 1.909. \\
\hline Conservative & & & 1.45902 & 1.861 & 2.085065 & $2.241 *$ \\
\hline Liberal & & & 0.47442 & 0.760 & 0.646727 & 1.015 \\
\hline Multiplatform & & & -0.34945 & -0.571 & -0.404756 & -0.657 \\
\hline $\begin{array}{l}\text { Trust } * \text { Oct } * \\
\text { mainstream }\end{array}$ & & & & & 0.038752 & 0.999 \\
\hline $\begin{array}{l}\text { Trust } * \text { Dec } * \\
\text { mainstream }\end{array}$ & & & & & 0.062280 & 1.605 \\
\hline $\begin{array}{l}\text { Trust } * \text { Jul * } \\
\text { mainstream }\end{array}$ & & & & & 0.008197 & 0.197 \\
\hline Intercept & 3.49528 & $5.478 * * *$ & 2.74292 & $2.883 * *$ & 3.139925 & $3.149 * *$ \\
\hline $\mathrm{R}^{2}$ & 0.2066 & & 0.2374 & & 0.2617 & \\
\hline
\end{tabular}

In summary, this study found that trustworthiness of a news source does not correlate with its frequent usage, answering RQ1. It offers support for part of H1, which hypothesizes trustworthiness is positively correlated with direct traffic, but does not offer support for a correlation between trust and frequent usage, as measured through usage minutes and days. Finding political ideology and multiplatform presence do not moderate the relationship between trust and direct traffic, and that being a mainstream news organization did moderate the relationship for one month, answered RQ2. 


\section{Chapter 5: Discussion}

News organizations today are grappling with how to rebuild eroding audience trust, which is at an all-time low for the news industry as a whole. A lack of trust can lead to damaged brand images and equities, as well as decreased revenue, for news organizations, especially as the Internet has lowered the barrier to entry for information sources and made countless alternatives easily accessible for news consumers to use. As news organizations implement strategies designed to increase trust, how can they best measure the impact of their efforts? This study contributes to this quandary by investigating the relationship between overall consumer trust of news sources and passive measures of usage, like those found in newsroom analytics reports. In doing so, it is one of the first media trust studies to rely on passive usage measures; previous research has predominantly relied on self-reports from news consumers, which allow for misremembrance and other inaccuracies and do not account for passive news consumption. It also integrates theories and concepts, such as bounded rationality and repertoires, that account for complications of news media choice that those in other studies, such as those relying on the uses and gratifications theory, may not. Further, the study's data reflect the more fragmented, curated and autonomous news environment of today; previous research mostly studied traditional platforms and distribution methods, findings from which are less applicable in today's evolving, digital-centric media environment.

This analysis provides evidence that trustworthiness of a news source has a positive association with its percentage of direct traffic; in other words, the more a news 
source is generally trusted, the more direct website traffic it receives. It also provides evidence that, at least in one month, being a mainstream news source could impact that relationship, but results are overall inconclusive. It does not provide evidence that multiplatform presence and political ideology significantly impact this relationship at all. Conversely, this analysis does not provide evidence of a relationship between trustworthiness of a news source and the frequency with which people visit. These findings and their theoretical contributions, larger implications and limitations of this study, and suggestions for future research are discussed below.

\section{Associations between trust and usage}

Consistent with the ideas of rational choice, repertoires and selective exposure, this study finds a positive correlation between trustworthiness of a news source and the amount of direct traffic it receives. When consumers use a rational decision-making process to choose what media to consume - by creating repertoires, probably based on a tendency to choose sources that reinforce existing beliefs - the amount of trust the public generally has in a news source impacts whether consumers make the active choice to visit a website directly. Therefore, higher direct traffic rates could be an indicator of increasing trustworthiness in an individual news source, which could help news organizations passively measure changes in audience trust.

In contrast, this study did not find any correlation between trustworthiness of a news source and the frequency with which people visit, as measured by the average number of minutes and days that consumers used each news source's website each month. These findings align with those in Williams' (2012) study, which found no association between trust of Internet news and attention. These findings also suggest that 
even though previous research (e.g., Tsfati, 2010) has found significant associations between exposure and skepticism, or distrust, the opposite - an association between exposure and trust - may not also be significant. In other words, trustworthiness of a news source may not have an impact on how long people spend on a news source's website or how many days each month someone visits it, even if distrust does. Therefore, these frequency measures may not help news organizations determine how generally trusted they are and, consequently, how strategies to build trust might have impacted how trusted they are.

Multiple factors could help explain these findings. First, supporting criticism of uses and gratifications theory, the frequency results indicate that visiting news sources' websites might not necessarily be an active process; people could passively consume websites through incidental exposure, such as on a social network's curated feed. However, when a visit is more intentional, such as a direct visit to a website, the process of choosing news media could be more active, leading people to more consciously consider options by using repertoires and bounded rationality. This could add to the media choice literature by highlighting differences between incidental and intentional media usage. Secondly, these results could eliminate self-reporting biases that were present in previous studies, which could provide a more accurate look at news consumption. This adds to the media trust and choice literature by contributing research based on more objective data than subjective self-reports. Third, the secondary trust and usage data are pooled cross-sectional data, meaning different populations comprise their representative samples (Wooldridge, 2012). The results could differ if panel data, or data from the same population sampled over time, were used (2012). Fourth, the 
trustworthiness measures used indicate how many people who have heard of a news source - not necessarily how many people who use that news source — trust it. Because of this, trust percentages for people who regularly use a news source could be different than the trust percentages for news sources used in this study.

\section{Impact of other factors on trust and usage}

In addition to testing the relationship between the trustworthiness of news organizations and usage, this study tested whether other variables moderated the relationship between the two. The following subsections discuss the effect of each additional variable tested.

Month. This study used variables with interactions between the percentage of trust and the month in which the data were taken because of significant differences in usage during the months sampled; the news websites sampled received significantly more direct traffic in July 2015 than in the other months sampled. Although several notable events happened during that month — such as the Greek referendum, the Women's World Cup and the Iranian nuclear deal — these events were not so numerous or significant to fully explain this difference in traffic (Josh, 2017). Therefore, this difference could reflect changing usage patterns at different periods of the year, such as when traveling during July and other summer months, celebrating holidays in December and other winter months, and adhering to a work routine in October and other months without holidays. This could contribute to literature on media usage by suggesting that usage habits are inconsistent across months; previous studies reviewed, relying on selfreported usage data, did not examine the possibility of usage varying across months. 
Thus, in future studies, multiple, and perhaps nonconsecutive, months should be examined when collecting samples from different periods in time.

Control Variables. Political ideology. This study found that being a news source with a majority conservative audience has a slightly significant positive correlation with the percentage of direct traffic it receives. This supports the idea of partisan selective exposure, or choosing to consume information that reinforces political beliefs and avoid information that challenges those beliefs (Garrett, 2009). However, the study also found no association between being a news source with a majority liberal audience and the percentage of direct traffic it receives, and it also found that the significant positive correlation between trustworthiness and usage remains when these two binary variables are added, with ideologically mixed news sources as the reference. When tested with interactions between trust, month and mainstream media, conservative ideology increases in significance, and all trust-month variables decrease in significance, with only July remaining significant.

This increased statistical significance for the conservative variable could be explained by a relationship between conservative news sources and mainstream news. There are fewer perceived "conservative" news sources than "liberal" news sources, as reflected in this study; 20 are coded as liberal, whereas six are coded as conservative. Additionally, five of six news sources coded as conservative were also coded as nonmainstream. Assuming partisan selective exposure holds true, and that the prevalence of nonmainstream conservative news sources is reflected across the news environment, conservatives may have more motivation to visit news sources that confirm pre-existing beliefs, many of which may be nonmainstream. Also, if conservatives are more skeptical 
of what they perceive to be "liberal" news sources, which were represented much more in this study and often coded as mainstream media, then they could be more likely to use “conservative," often nonmainstream sources that reaffirm existing beliefs. This would align with the research from Tsfati and Cappella (2003, 2005) and Tsfati (2010) that mainstream news skeptics consume more nonmainstream news than non-skeptics.

No change in the relationship between overall trust and usage with the presence of control variables suggests partisanship might not significantly impact the relationship. However, multiple factors should be considered. First, this study's trust measures are of people who have heard of - not necessarily people who use - a news source. If this study used trust measures segmented by political ideology, results could differ. Second, news sources did not self-identify the political ideologies; they may not acknowledge political biases or realize subtle ones. Instead, this study uses the primary identity of people who reported using news sources weekly, collected as part of the Pew study, under the assumption that partisan selective exposure helps drive media choice. It does not account, however, for news sources that have nonpartisan coverage and coincidentally might have a predominantly conservative or liberal audience, or for people who might read varying news sources to understand viewpoints across the political spectrum. Third, Pew and ComScore data come from different sample populations, so there could be different results if the same population were surveyed. In any event, these findings add to media choice and usage literature by suggesting a news source's political ideology could impact usage measures but not alter any relationship between trustworthiness and usage. 
Multiplatform. This study found that being a news source with a presence on multiple platforms, versus being a news source with only an online presence, does not impact the relationship between trustworthiness and usage. This supports the idea that trustworthiness and usage of news sources online does not differ between multiplatform news sources, which tend to be traditional, legacy news sources, and online-only ones, which tend to be newer news sources. This adds to the media usage literature by suggesting that online audiences of multiplatform news sources and online audiences of online-only news sources are comparable when it comes to the relationship between trustworthiness and usage.

Mainstream News. Because this study finds the relationship between trustworthiness and direct traffic changes only when mainstream news is interacted with trust and July, this study is unable to conclude whether it moderates the relationship. Moderating the relationship would align with findings from Tsfati and Cappella (2003, 2005) and Tsfati (2010) that skeptics consume more nonmainstream news than nonskeptics, or the opposite, that non-skeptics would consume more mainstream news. One explanation for these inconsistent results could be the lack of a universal definition of "mainstream" and "nonmainstream," so news source classifications could vary among studies. Previous research also did not explicitly define mainstream and nonmainstream news as this study did, which could have resulted in different interpretations of the terms. This study adds to the literature by testing this variable under more detailed definitions than those in previous studies. 


\section{Suggestions for Future Research}

In examining the relationship between news media trustworthiness and usage, this study broadly found a significant and positive association between trustworthiness of a news source and direct traffic, as well as no association between overall trust and frequent usage. This helps shed light on ways news organizations could — and shouldn't - gauge how much they are trusted and the effectiveness of strategies to improve trust. The results of this study are first steps that could lead to further research in this area, which has not been studied extensively at this point.

This study differed from previous ones in that it used representative data to look at relationships between trustworthiness and usage for the overall population instead of collecting individual user data. Although this is a limitation in that it cannot control for demographics or motivations, it does answer a different type of question than those previously posed that focus on specific users. To minimize potential discrepancies between different sample populations and control for demographic and motivational factors, future researchers could use the same sample population of individual users for all measures, asking them which news sources they trust and installing tracking software to passively measure their media usage. By doing this, researchers could better identify trust of news organizations by segmented population, and not use trustworthiness of news sources via a representative sample, as well as better identify trust and usage relationships on individual levels rather than as a general population of news consumers. However, future research could also construct similar representative data sets to examine the impact of gender or other demographic factors on the relationship between trustworthiness and usage for the overall population. 
Future studies could also use more updated data. The Pew Research Center data were collected in early 2014, and the ComScore data were collected from late 2014 to mid-2015. These trust and usage measures occurred before the 2016 United States presidential election season, during which trust and usage of news sources, particularly those with articles that could have furthered political polarization, could have changed. During this time, some of the newer online news sources, such as BuzzFeed and Breitbart, could have expanded both in coverage and audience size. Collecting trust and usage data after this time period could provide more insight into today's media environment than the data used in this study. Comparing the relationship between trust and usage before and after the election could also test whether the election impacted trust and usage of media organizations, as well as test whether the election impacted the effect of political ideology on the relationship between trust and usage. 


\section{References}

Benoit, K. (2011). Linear Regression Models with Logarithmic Transformations. Kenneth Benoit: Political Science Home Page. Retrieved from http://www.kenbenoit.net/courses/ME104/logmodels2.pdf.

Blumler, J.G. (1979). The role of theory in uses and gratifications studies. Communication Research, 6(1), 9-36.

Blumler, J.G., Gurevitch, M., \& Katz, E. (1973). Uses and Gratifications Research. Public Opinion Quarterly, 37(4), 509-523.

Cronk, B. (2014). How to Use SPSS: A Step-by-Step Guide to Analysis and Interpretation ( $8^{\text {th }}$ ed.). Glendale, CA: Pyrczak Publishing.

Coe, K., Tewksbury, D., Bond, B., Drogos, K., Porter, R., Yahn, A., \& Zhang, Y. (2008). Hostile News: Partisan Use and Perceptions of Cable News Programming. Journal of Communication, 58(2), 201-219.

Coleman, J.S. (1990). Foundations of social theory. Cambridge, MA: Belknap Press of Harvard University Press.

ComScore. (n.d.). ComScore Facts at a Glance. ComScore. Retrieved from http://www.comscore.com/About-comScore/comScore-Facts-at-a-Glance.

ComScore. (n.d.). ComScore Media Metrix Description of Methodology: Unified Digital Measurement. Pew Research Center. Retrieved from http://www.journalism.org/files/2014/03/comScore-Media-Metrix-Description-ofMethodology.pdf.

ComScore. (n.d.). ComScore Unified Digital Measurement Methodology. ComScore. Retrieved from http://www.comscore.com/Media/Files/Misc/comScore-UnifiedDigital-Measurement-Methodology-PDF?cs_edgescape_cc=US.

ComScore. (n.d.). Media Metrix. ComScore. Retrieved from https://www.comscore.com/Products/Audience-Analytics/Media-Metrix.

ComScore. (n.d.). Media Metrix Source/Loss Report. ComScore. Retrieved from https://gm1.geolearning.com/geonext/comscore/displaywidgetpage.geo?id=0PF4F XFtUg\%2fQAbTLHeOpC2GYQkRh0N5edfoJK\%2fsmGioisNjnVBWNWw\%3d $\% 3 d \& n a v=$ MediaMetrixSC92211.

Daily Kos. (n.d.). Masthead. Daily Kos. Retrieved from http://www.dailykos.com/masthead\#dk. 
Dowmunt, T., \& Coyer, K. (2007). Introduction. In K. Coyer, T. Dowmunt \& A. Fountain (Eds.), The Alternative Media Handbook (pp. 1-12). New York: Routledge.

Garrett, R.K. (2009). Echo chambers online?: Politically motivated selective exposure among Internet news users. Journal of Computer-Mediated Communication, $14(2), 265-285$.

Garrett, R.K. (2006a, November). Avoiding political difference: Characteristics associated with reduced exposure to opinion-contrary information. Paper presented at National Communication Association annual meeting, San Antonio, TX.

Garrett, R.K. (2006b, June). Seeking similarity, not avoiding difference: Reframing the selective exposure debate. Paper presented at the International Communication Association annual conference, Dresden, Germany.

Giddens, A. (1984). The constitution of society: Outline of the theory of structuration. Berkeley, CA: University of California Press.

Hovland, C.I., \& Weiss, W. (1951). The influence of source credibility of communication effectiveness. Public Opinion Quarterly, 15, 633-650.

Josh, J. (2015). Current Affairs July 2015. Retrieved from https://books.google.com/books?id=VYTdCgAAQBAJ\&lpg=PA20\&ots=rpJ0M W52Is \&dq=july\%202015\%20current $\% 20$ events\&pg=PA20\#v=onepage \&q\&f=fal se.

Kenix, L.J. (2012). Alternative and Mainstream Media: The converging spectrum. London, England: Bloomsbury.

Kim, S. (2016). A repertoire approach to cross-platform media use behavior. New Media \& Society, 18(3), 353-372.

Kim, G., Shin, B., \& Lee, H.G. (2009). Understanding dynamics between initial trust and usage intentions of mobile banking. Information Systems Journal, 19: 283-311.

Kiousis, S. (2001). Public trust or mistrust? Perceptions of media credibility in the Information Age. Mass Communication \& Society, 4(4): 381-403.

Kohring, M., \& Matthes, J. (2007). Trust in news media development and validation of a multidimensional scale. Communication Research, 34(2), 231-252.

Kovach, B., \& Rosenstiel, T. (2007). The Elements of Journalism: What Newspeople Should Know and the Public Should Expect. New York: Three Rivers Press. 
Lacy, S. (1993). Understanding \& serving readers: The problem of fuzzy market structure. Newspaper Research Journal, 14(2), 55-67.

Liebes, T. (2001). Inside a news item: A dispute over framing. Political Communication, 17, 295-305.

Lometti, G.E., Reeves, B., \& Bybee, C.R. (1977). Investigating the assumptions of uses and gratifications research. Communication Research, 4(3), 321-338.

Lupia, A., \& McCubbins, M.D. (1998). The democratic dilemma: Can citizens learn what they need to know? Cambridge, MA: Cambridge University Press.

Media Insight Project. (2016, April 17). A new understanding: What makes people trust and rely on news. American Press Institute. Retrieved from https://www.americanpressinstitute.org/publications/reports/survey-research/trustnews.

Mitchell, A., Gottfried, J., Kiley, J., \& Matsa, K.E. (2014, October 21). Political Polarization \& Media Habits. Pew Research Center. Retrieved from http://www.journalism.org/2014/10/21/political-polarization-media-habits.

Napoli, P. (2011). Audience Evolution: New Technologies and the Transformation of Media Audiences. New York: Columbia University Press.

Newell, A., \& Simon, H.A. (1972). Human problem-solving. Englewood Cliffs, NJ: Prentice-Hall.

Pew Research Center. (2014, October 21). Where News Audiences Fit on the Political Spectrum. Pew Research Center. Retrieved from http://www.journalism.org/interactives/media-polarization/outlet/abc-news.

Pew Research Center. (n.d.). About Pew Research Center. Pew Research Center. Retrieved from http://www.pewresearch.org/about.

Reagan, J. (1996). The "repertoire" of information sources. Journal of Broadcasting and Electronic Media, 40(1): 112-121.

Rover, C. (2011, March 3). Publishers making profits: Mother Jones. Digiday. Retrieved from http://digiday.com/platforms/publishers-making-profits-mother-jones.

Self, C.C. (1996). Credibility. In M.B. Salwen, \& D.W. Stacks (Eds.), An integrated approach to communication theory and research (pp. 421-444). Mahweh, NJ: Lawrence Erlbaum. 
Slater, M.D. (2007). Reinforcing spirals: The mutual influence of media selectivity and media effects and their impact on individual behavior and social identity. Communication Theory, 17: 281-303.

Stroud, N.J. (2008). Media Use and Political Predispositions: Revisiting the Concept of Selective Exposure. Political Behavior, 30: 341-366.

Swift, A. (2016, September 14). Americans' Trust in Mass Media Sinks to New Low. Gallup. Retrieved from http://www.gallup.com/poll/195542/americans-trustmass-media-sinks-new-low.aspx.

Taneja, H., Webster, J., Malthouse, E., \& Ksiazek, T. (2012). Media consumption across platforms: Identifying user-defined repertoires. New Media \& Society, 14(6), 951968.

The Ed Schultz Show. (n.d.). About Ed. The Ed Schultz. Show. Retrieved from http://wegoted.com/about-ed.

The Pew Charitable Trusts. (n.d.). Mission \& Values. The Pew Charitable Trusts. Retrieved from http://www.pewtrusts.org/en/about/mission-and-values.

Tsfati, Y., \& Cappella, J.N. (2003). Do people watch what they do not trust? Exploring the association between news media skepticism and exposure. Communication Research, 30(5), 504-529.

Tsfati, Y., \& Cappella, J.N. (2005). Why do people watch news they do not trust? The need for cognition as a moderator in the association between news media skepticism and exposure. Media Psychology, 7(3), 251-271.

Tsfati, Y. (2010). Online news exposure and trust in the mainstream media: Exploring possible associations. American Behavioral Scientist, 54(1), 22-42.

Webster, J.G. (2014). The marketplace of attention: How audiences take shape in a digital age. Cambridge, MA: MIT Press.

Webster, J.G. (2011). The duality of media: A structurational theory of public attention. Communication Theory, 21:43-66.

Webster, J.G., \& Ksiazek, T.B. (2012). The dynamics of audience fragmentation: Public attention in an age of digital media. Journal of Communication, 62: 39-56.

Williams, A.E. (2012). Trust or bust? Questioning the relationship between media trust and news attention. Journal of Broadcasting \& Electronic Media, 56(1): 116-131. 
Wildman, S. S., \& Owens, B. M. (1992). Video economics. Cambridge, MA: Harvard University Press.

Wolling, J. (2009). The effect of subjective quality assessments. In T. Hartmann (Ed.), Media choice: A theoretical and empirical overview (pp. 84-101). New York, NY: Routledge.

Wooldridge, J.M. (2012). Introductory Econometrics: A Modern Approach ( $\left.5^{\text {th }} \mathrm{ed}\right)$. Mason, OH: South-Western, Cengage Learning. 


\section{Appendix A: Data Codebook}

\section{MediaOutlet (A)}

- $\quad$ ABC News $=[\mathrm{SG}]$ ABCNEWS.COM

- Al Jazeera America $=[\mathrm{M}]$ Aljazeera America

- $\quad \mathrm{BBC}=[\mathrm{C}] \mathrm{BBC}$ News

- $\quad$ The Blaze $=[\mathrm{M}]$ THEBLAZE.COM

- Bloomberg $=[\mathrm{C}]$ BLOOMBERG.COM

- $\quad$ Breitbart $=[\mathrm{P}]$ BREITBART.COM

- BuzzFeed $=[$ P] BUZZFEED.COM

- $\quad$ CBS News $=[\mathrm{S}]$ CBSNEWS.COM

- $\mathrm{CNN}=[\mathrm{M}] \mathrm{CNN}$.COM

- The Colbert Report $=[\mathrm{S}]$ Colbert Nation

- Daily Kos = [M] DAILYKOS.COM

- The Daily Show = [S] The Daily Show

- Drudge Report $=[\mathrm{P}]$ DRUDGEREPORT.COM

- $\quad$ The Economist $=[\mathrm{M}]$ ECONOMIST.COM

- The Ed Schultz Show = [S] The Ed Show

- Fox News Cable Channel = [M] FOXNEWS.COM

- The Glenn Beck Program = [M] GLENNBECK.COM

- Google News $=[\mathrm{S}]$ Google News Search

- The Guardian $=[\mathrm{M}]$ THEGUARDIAN.COM

- $\quad$ The Huffington Post = SUM OF THE FOLLOWING:

- $\quad[C]$ HuffPost Arts \& Culture

- [C] HuffPost Books

- [C] HuffPost Crime

- [C] HuffPost Entertainment

- [C] HuffPost Green

- $\quad[C]$ HuffPost Live

- [C] HuffPost Multicultural

- $\quad[C]$ HuffPost Politics

- [C] HuffPost Sports

- [C] HuffPost Weird News

- [C] HuffPost WorldPost

- Mother Jones $=[\mathrm{M}]$ MOTHERJONES.COM

- $\mathrm{MSNBC}=[\mathrm{C}] \mathrm{MSNBC}$ TV

- $\quad$ NBC News $=[C]$ NBCNEWS.COM

- The New York Times = [C] NYTIMES.COM

- The New Yorker $=[\mathrm{C}]$ NEWYORKER.COM

- $\quad \mathrm{NPR}=[\mathrm{M}] \mathrm{NPR} . \mathrm{ORG}$

- $\quad \mathrm{PBS}=[\mathrm{C}]$ PBS NewsHour 
- Politico $=[\mathrm{M}]$ POLITICO.COM

- The Rush Limbaugh Show = [M] RUSHLIMBAUGH.COM

- Slate $=[C]$ SLATE.COM

- $\quad$ ThinkProgress $=[\mathrm{P}]$ THINKPROGRESS.ORG

- USA Today $=[\mathrm{C}]$ USA TODAY News

- The Wall Street Journal = [S] WSJ.COM

- The Washington Post $=[\mathrm{P}]$ WASHINGTONPOST.COM

- Yahoo News $=[\mathrm{S}]$ Yahoo News

Month_OCT14 (B):

- $\quad 1=$ data collected in October 2014

- $\quad 0=$ data not collected in October 2014

\section{Month_DEC14 (C):}

- $\quad 1$ = data collected in December 2014

- $0=$ data not collected in December 2014

\section{Month_JUL15 (D):}

- 1 = data collected in July 2015

- 0 = data not collected in July 2015

Adj_Overall_T (E): The overall percentage of people surveyed who trust a news source, adjusted to be out of the people who have heard of that news source. This was determined by calculating [Overall_T/(Overall_T +Overall_DT +Overall_N $)]$.

Adj_Overall_DT (F): The overall percentage of people surveyed who do not trust a news source, adjusted to be out of the people who have heard of that news source. This was determined by calculating [Overall_DT / Overall_T +Overall_DT + Overall_N $)]$.

Adj_Overall_N (G): The overall percentage of people surveyed who neither trust nor distrust a news source, adjusted to be out of the people who have heard of that news source. This was determined by calculating [Overall_N/(Overall_T +Overall_DT + Overall_N)].

Overall_T (H): The overall percentage of people surveyed who trust a news source. Data retrieved from http://www.journalism.org/2014/10/21/political-polarization-mediahabits/pj_14-10-21_mediapolarization-10/.

Overall_DT (I): The overall percentage of people surveyed who do not trust a news source. Data retrieved from http://www.journalism.org/2014/10/21/political-polarizationmedia-habits/pj 14-10-21 mediapolarization-10/. 
Overall_N (J): The overall percentage of people surveyed who neither trust nor distrust a news source. Data retrieved from http://www.journalism.org/2014/10/21/politicalpolarization-media-habits/pj_14-10-21_mediapolarization-10/.

Adj_Lib_T (K): The percentage of people identified as consistently liberal or mostly liberal who trust a news source, adjusted to be out of the people who have heard of that news source. This was determined by calculating $\left[L i b \_T /\left(L i b \_T+L i b \_D T+L i b \_N\right)\right]$.

Adj_Lib_DT (L): The percentage of people identified as consistently liberal or mostly liberal who do not trust a news source, adjusted to be out of the people who have heard of that news source. This was determined by calculating $\left[L i b \_D T /\left(L i b \_T+L i b \_D T+\right.\right.$ $\left.\left.L i b \_N\right)\right]$.

Adj_Lib_N (M): The percentage of people identified as consistently liberal or mostly liberal who neither trust nor distrust a news source, adjusted to be out of the people who have heard of that news source. This was determined by calculating [Lib_N/(Lib_T + $\left.\left.L i b \_D T+L i b \_N\right)\right]$.

Lib_T (N): The percentage of people identified as consistently liberal or mostly liberal who trust a news source. This was determined by calculating $\left[\left(C L \_T / 100\right) *(16 / 100)+\right.$ $\left.\left(M L \_T / 100\right) *(22 / 100)\right] * 100$.

Lib_DT (O): The percentage of people identified as consistently liberal or mostly liberal who do not trust a news source. This was determined by calculating $\left[\left(C L \_D T / 100\right) *\right.$ $\left.(16 / 100)+\left(M L \_D T / 100\right) *(22 / 100)\right] * 100$.

Lib_N (P): The percentage of people identified as consistently liberal or mostly liberal who neither trusts nor distrusts a news source. This was determined by calculating $\left[\left(C L \_N / 100\right) *(16 / 100)+\left(M L \_N / 100\right) *(22 / 100)\right] * 100$.

Lib_NH (Q): The percentage of people identified as consistently liberal or mostly liberal who have not heard of a news source. This was determined by calculating $\left[\left(C L \_N H / 100\right)\right.$ $\left.*(16 / 100)+\left(M L \_N H / 100\right) *(22 / 100)\right] * 100$.

CL_T (R): The percentage of people identified as consistently liberal who trust a news source. Data retrieved from http://www.journalism.org/2014/10/21/political-polarizationmedia-habits/pj_2014-10-21_media-polarization-36/ and http://www.journalism.org/interactives/media-polarization/table/trust/.

CL_DT (S): The percentage of people identified as consistently liberal who do not trust a news source. Data retrieved from http://www.journalism.org/2014/10/21/politicalpolarization-media-habits/pj_2014-10-21_media-polarization-36/ and http://www.journalism.org/interactives/media-polarization/table/distrust/.

CL_N (T): The percentage of people identified as consistently liberal who neither trust nor distrust a news source. Data retrieved from 
http://www.journalism.org/2014/10/21/political-polarization-media-habits/pj_2014-1021_media-polarization-36/.

CL_NH (U): The percentage of people identified as consistently liberal who have not heard of a news source. Data retrieved from http://www.journalism.org/2014/10/21/political-polarization-media-habits/pj_2014-1021_media-polarization-36/.

ML_T (V): The percentage of people identified as mostly liberal who trust a news source. Data retrieved from http://www.journalism.org/2014/10/21/political-polarizationmedia-habits/pj_2014-10-21_media-polarization-39/ and http://www.journalism.org/interactives/media-polarization/table/trust/.

ML_DT (W): The percentage of people identified as mostly liberal who do not trust a news source. Data retrieved from http://www.journalism.org/2014/10/21/politicalpolarization-media-habits/pj_2014-10-21_media-polarization-39/ and http://www.journalism.org/interactives/media-polarization/table/distrust/.

ML_N (X): The percentage of people identified as mostly liberal who neither trust nor distrust a news source. Data retrieved from http://www.journalism.org/2014/10/21/political-polarization-media-habits/pj_2014-1021 media-polarization-39/.

ML_NH (Y): The percentage of people identified as mostly liberal who have not heard of a news source. Data retrieved from http://www.journalism.org/2014/10/21/politicalpolarization-media-habits/pj_2014-10-21_media-polarization-39/.

Adj_Mixed_T (Z): The percentage of people identified as ideologically mixed who trust a news source, adjusted to be out of the people who have heard of that news source. This was determined by calculating [Mixed_T/Mixed_T + Mixed_DT + Mixed_N)].

Adj_Mixed_DT (AA): The percentage of people identified as ideologically mixed who do not trust a news source, adjusted to be out of the people who have heard of that news source. This was determined by calculating [Mixed_DT/Mixed_T + Mixed_DT + Mixed_N)].

Adj_Mixed_N (AB): The percentage of people identified as ideologically mixed who do not trust a news source, adjusted to be out of the people who have heard of that news source. This was determined by calculating [Mixed_N/Mixed_T + Mixed_DT + Mixed_N)].

Mixed_T (AC): The percentage of people identified as ideologically mixed who trust a news source. Data retrieved from the Complete Report PDF (accessed from http://www.journalism.org/2014/10/21/political-polarization-media-habits/) and http://www.journalism.org/interactives/media-polarization/table/trust/. 
Mixed_DT (AD): The percentage of people identified as ideologically mixed who do not trust a news source. Data retrieved from the Complete Report PDF (accessed from http://www.journalism.org/2014/10/21/political-polarization-media-habits/) and http://www.journalism.org/interactives/media-polarization/table/distrust/.

Mixed_N (AE): The percentage of people identified as ideologically mixed who neither trust nor distrust a news source. Data retrieved from the Complete Report PDF (accessed from http://www.journalism.org/2014/10/21/political-polarization-media-habits/) and http://www.journalism.org/interactives/media-polarization/table/mixed/.

Mixed_NH (AF): The percentage of people identified as ideologically mixed who have not heard of a news source. Data retrieved from the Complete Report PDF (accessed from http://www.journalism.org/2014/10/21/political-polarization-media-habits/) and http://www.journalism.org/interactives/media-polarization/table/mixed/.

Adj_Con_T (AG): The percentage of people identified as consistently conservative or mostly conservative who trust a news source, adjusted to be out of the people who have heard of that news source. This was determined by calculating [Con_T/(Con_T+ Con_DT + Con_N)].

Adj_Con_DT (AH): The percentage of people identified as consistently conservative or mostly conservative who do not trust a news source, adjusted to be out of the people who have heard of that news source. This was determined by calculating [Con_DT / $C O n_{-} T+$ Con_DT + Con_N)].

Adj_Con_N (AI): The percentage of people identified as consistently conservative or mostly conservative who neither trust nor distrust a news source, adjusted to be out of the people who have heard of that news source. This was determined by calculating [Con_N/ $\left.\left(C o n \_T+C o n \_D T+C o n \_N\right)\right]$.

Con_T (AJ): The percentage of people identified as consistently conservative or mostly conservative who trust a news source. This was determined by calculating $\left[\left(C C_{-} T / 100\right)\right.$ * $\left.(9 / 100)+\left(M C_{-} T / 100\right) *(17 / 100)\right] * 100$.

Con_DT (AK): The percentage of people identified as consistently conservative or mostly conservative who do not trust a news source. This was determined by calculating $\left[\left(C C_{-} D T / 100\right) *(9 / 100)+\left(M C_{-} D T / 100\right) *(17 / 100)\right] * 100$.

Con_N (AL): The percentage of people identified as consistently conservative or mostly conservative who neither trust nor distrust a news source. This was determined by calculating $\left[\left(C C_{-} N / 100\right) *(9 / 100)+\left(M C_{-} N / 100\right) *(17 / 100)\right] * 100$.

Con_NH (AM): The percentage of people identified as consistently conservative or mostly conservative who have not heard of a news source. This was determined by calculating $\left[\left(C C \_N H / 100\right) *(9 / 100)+\left(M C \_N H / 100\right) *(17 / 100)\right] * 100$. 
MC_T (AN): The percentage of people identified as mostly conservative who trust a news source. Data retrieved from http://www.journalism.org/2014/10/21/politicalpolarization-media-habits/pj_2014-10-21_media-polarization-40/ and http://www.journalism.org/interactives/media-polarization/table/trust/.

MC_DT (AO): The percentage of people identified as mostly conservative who do not trust a news source. Data retrieved from http://www.journalism.org/2014/10/21/politicalpolarization-media-habits/pj_2014-10-21_media-polarization-40/ and http://www.journalism.org/interactives/media-polarization/table/distrust/.

MC_N (AP): The percentage of people identified as mostly conservative who neither trust nor distrust a news source. Data retrieved from http://www.journalism.org/2014/10/21/political-polarization-media-habits/pj_2014-1021 media-polarization-40/.

MC_NH (AQ): The percentage of people identified as ideologically mixed who have not heard of a news source. Data retrieved from http://www.journalism.org/2014/10/21/political-polarization-media-habits/pj2014-1021_media-polarization-40/.

CC_T (AR): The percentage of people identified as consistently conservative who trust a news source. Data retrieved from http://www.journalism.org/2014/10/21/politicalpolarization-media-habits/pj_2014-10-21_media-polarization-41/ and http://www.journalism.org/interactives/media-polarization/table/trust/

CC_DT (AS): The percentage of people identified as consistently conservative who do not trust a news source. Data retrieved from http://www.journalism.org/2014/10/21/political-polarization-media-habits/pj_2014-1021_media-polarization-41/ and http://www.journalism.org/interactives/mediapolarization/table/distrust/.

CC_N (AT): The percentage of people identified as consistently conservative who neither trust nor distrust a news source. Data retrieved from http://www.journalism.org/2014/10/21/political-polarization-media-habits/pj_2014-1021_media-polarization-41/ and http://www.journalism.org/interactives/mediapolarization/table/consistently-conservative/.

CC_NH (AU): The percentage of people identified as ideologically mixed who have not heard of a news source. Data retrieved from http://www.journalism.org/2014/10/21/political-polarization-media-habits/pj_2014-1021_media-polarization-41/ and http://www.journalism.org/interactives/mediapolarization/table/consistently-conservative/.

MSM (AV):

- $\quad 1$ = classified as mainstream media (e.g., larger, having more formulaic content) 
- $\quad 0=$ classified as nonmainstream/alternative media (e.g., smaller, offers more analysis, may advocate or wish to cause social change)

Audience_L (AW): The percentage of people who use the media source in a typical week who identify as consistently or mostly liberal. Data retrieved from http://www.journalism.org/interactives/media-polarization/outlet/washington-post/ (for each media outlet).

- Note: The percentage for Slate is also being used for Daily Kos, Mother Jones and ThinkProgress, for which Pew did not calculate percentages, because of their audience overlap.

- Note: The percentage for MSNBC is also being used for The Ed Schultz Show, for which Pew did not calculate a percentage, because of their audience overlap. The Ed Schultz Show's website is also hosted by MSNBC.

Audience_M (AX): The percentage of people who use the media source in a typical week who identify as ideologically mixed. Data retrieved from http://www.journalism.org/interactives/media-polarization/outlet/washington-post/ (for each media outlet).

- Note: The percentage for Slate is also being used for Daily Kos, Mother Jones and ThinkProgress, for which Pew did not calculate percentages, because of their audience overlap.

- Note: The percentage for MSNBC is also being used for The Ed Schultz Show, for which Pew did not calculate a percentage, because of their audience overlap. The Ed Schultz Show's website is also hosted by MSNBC.

Audience_C (AY): The percentage of people who use the media source in a typical week who identify as consistently or mostly conservative. Data retrieved from http://www.journalism.org/interactives/media-polarization/outlet/washington-post/ (for each media outlet).

- Note: The percentage for Slate is also being used for Daily Kos, Mother Jones and ThinkProgress, for which Pew did not calculate percentages, because of their audience overlap.

- Note: The percentage for MSNBC is also being used for The Ed Schultz Show, for which Pew did not calculate a percentage, because of their audience overlap. The Ed Schultz Show's website is also hosted by MSNBC.

\section{DumAudL (AZ):}

- $1=$ classified as having an audience with more liberal users than those of other political ideologies (as determined from values in columns AW-AY).

- $0=$ classified as having an audience with more users of another political ideology

\section{DumAudM (BA):}


- 1 = classified as having an audience with more ideologically mixed users than those of other political ideologies (as determined from values in columns AWAY).

- $0=$ classified as having an audience with more users of another political ideology

\section{DumAudC (BB):}

- $1=$ classified as having an audience with more conservative users than those of other political ideologies (as determined from values in columns AW-AY).

- $0=$ classified as having an audience with more users of another political ideology

\section{Show (BC):}

- $1=$ classified as a show that is part of a larger news source, i.e., broadcast on a television station or radio station

- $0=$ not classified as a show

\section{Multiplatform (BD):}

- $1=$ has a presence on multiple platforms, i.e., online and television/print media/radio

- $0=$ has a presence online only

UsageDays (BE): The average number of days a person visits a website in a given month, as determined by ComScore Media Metrix's "Average Usage Days per Visitor" metric.

- Note: The Huffington Post's data is the average of usage days for all channels measured in October 2014, December 2014 and July 2015: HuffPost Arts \& Culture, HuffPost Books, HuffPost Crime, HuffPost Entertainment, HuffPost Green, HuffPost Live, HuffPost Multicultural, HuffPost Politics, HuffPost Sports, HuffPost Weird News, HuffPost World.

Minutes (BC): The average number of minutes a person uses a website in a given month, as determined by ComScore Media Metrix's "Average Minutes per Visitor" metric.

- Note: The Huffington Post's data is the average of usage days for all channels measured in October 2014, December 2014 and July 2015: HuffPost Arts \& Culture, HuffPost Books, HuffPost Crime, HuffPost Entertainment, HuffPost Green, HuffPost Live, HuffPost Multicultural, HuffPost Politics, HuffPost Sports, HuffPost Weird News, HuffPost World.

DirectTraffic (BD): The percentage of people who access a website directly, and not through a third-party referral (e.g., social network, another website), as determined by ComScore Media Metrix's “\% of Entries" metric for the "Logon" source of incoming traffic.

- Note: The Huffington Post's data is the average of usage days for all channels measured in October 2014, December 2014 and July 2015: HuffPost Arts \& 
Culture, HuffPost Books, HuffPost Crime, HuffPost Entertainment, HuffPost Green, HuffPost Live, HuffPost Multicultural, HuffPost Politics, HuffPost Sports, HuffPost Weird News, HuffPost World.

TotalUniqueVisitors (BE): The number of unique visitors a website received during a given month.

- Note: The Huffington Post's data is the average of usage days for all channels measured in October 2014, December 2014 and July 2015: HuffPost Arts \& Culture, HuffPost Books, HuffPost Crime, HuffPost Entertainment, HuffPost Green, HuffPost Live, HuffPost Multicultural, HuffPost Politics, HuffPost Sports, HuffPost Weird News, HuffPost World. 


\section{Appendix B: Cross-Visitation Tables}

October 2014 Cross-Visitation Calculations

\begin{tabular}{|c|c|c|c|c|c|c|}
\hline$\frac{\text { Source1 }}{\text { SLATE }}$ & $\underline{\text { Source2 }}$ & Audience1 & Audience2 & $\frac{\text { Expected }}{\text { Shared }}$ & $\begin{array}{l}\text { Actual } \\
\text { Shared }\end{array}$ & Expected:Actual \\
\hline COM & DAILYKOS.COM & 0.076 & 0.009 & 171,421 & 564,429 & 0.304 \\
\hline SLATE & MOTHERJONES & & & & & \\
\hline $\begin{array}{l}. \text { COM } \\
\text { SLATE }\end{array}$ & $\begin{array}{c}. \text { COM } \\
\text { THINKPROGRESS }\end{array}$ & 0.076 & 0.01 & 190,467 & $1,032,952$ & 0.184 \\
\hline $\begin{array}{l}\text { COM } \\
\text { MSNBC }\end{array}$ & .ORG & 0.076 & 0.027 & 514,262 & $1,269,311$ & 0.405 \\
\hline TV & The Ed Show & 0.032 & 0.001 & 8,020 & 299,875 & 0.027 \\
\hline
\end{tabular}

Note: Total Internet Audience $=250,615,000$

December 2014 Cross-Visitation Calculations

\begin{tabular}{|c|c|c|c|c|c|c|}
\hline$\frac{\text { Source1 }}{\text { SLATE }}$ & Source2 & Audience1 & Audience2 & $\frac{\text { Expected }}{\text { Shared }}$ & $\begin{array}{l}\text { Actual } \\
\text { Shared }\end{array}$ & Expected:Actua \\
\hline. $\mathrm{COM}$ & DAILYKOS.COM & 0.065 & 0.009 & 147,694 & 395,460 & 0.373 \\
\hline SLATE & MOTHERJONES & & & & & \\
\hline $\begin{array}{l}\text { COM } \\
\text { SLATE }\end{array}$ & $\begin{array}{c}\text {.COM } \\
\text { THINKPROGRESS }\end{array}$ & 0.065 & 0.009 & 147,694 & 671,532 & 0.22 \\
\hline $\begin{array}{l}\text { COM } \\
\text { MSNBC }\end{array}$ & .ORG & 0.065 & 0.024 & 393,852 & $3,490,656$ & 0.113 \\
\hline TV & The Ed Show & 0.033 & 0.001 & 8,331 & 184,885 & 0.045 \\
\hline
\end{tabular}

Note: Total Internet Audience $=252,469,000$

July 2015 Cross-Visitation Calculations

\begin{tabular}{|c|c|c|c|c|c|c|}
\hline$\frac{\text { Source1 }}{\text { SLATE }}$ & Source2 & Audience1 & Audience2 & $\frac{\text { Expected }}{\text { Shared }}$ & $\begin{array}{l}\text { Actual } \\
\text { Shared }\end{array}$ & Expected:Actual \\
\hline. $\mathrm{COM}$ & DAILYKOS.COM & 0.07 & 0.016 & 287,811 & 727,483 & 0.396 \\
\hline SLATE & MOTHERJONES & & & & & \\
\hline .COM & .COM & 0.07 & 0.027 & 485,681 & $1,375,690$ & 0.353 \\
\hline SLATE & THINKPROGRESS & & & & & \\
\hline. $\mathrm{COM}$ & .ORG & 0.07 & 0.027 & 485,681 & $1,737,231$ & 0.28 \\
\hline
\end{tabular}

Note: Total Internet Audience $=256,974,000$

Key:

- Audience 1 = percentage of total Internet audience that used Source1

- Audience 2 = percentage of total Internet audience that used Source2 
- Expected Shared $=($ Audience $1 *$ Audience 2$) *$ Total Internet Audience

- Actual Shared = number of shared audience members obtained from ComScore report

- $\quad$ Expected:Actual $=$ Expected Shared $/$ Actual Shared 